\title{
Minerais pesados de saprólitos de pegmatitos intrusivos no ortognaisse Resende Costa: caracterização e correlação com a Província Pegmatítica de São João del Rei, Minas Gerais, Brasil
} Heavy minerals of saprolites of pegmatites intrusive in the Resende Costa Orthogneiss: characterization and correlation with the São João del Rei Pegmatitic Province, Minas Gerais State, Brazil

\author{
Taís Proença Cidade ${ }^{1,2}$ (D), Ciro Alexandre Ávila ${ }^{1,3}$ (D), Reiner Neumann"1,2 (D), Fabiano Richard Leite Faulstich ${ }^{1}$ (D), \\ Victor Hugo Riboura Menezes da Silva ${ }^{3}$ (D), Sarah Siqueira da Cruz Guimarães Sousa ${ }^{1,3}$ (D) \\ ${ }^{1}$ Universidade Federal do Rio de Janeiro - UFRJ, Museu Nacional, Departamento de Geologia e Paleontologia, Programa de \\ Pós-Graduação em Geociências e Patrimônio Geopaleontológico, Quinta da Boa Vista, s/n, São Cristóvão, CEP 20940-040, \\ Rio de Janeiro, RJ, BR (taiscidade1@gmail.com; avila@mn.ufrj.br; rneumann@cetem.gov.br; ffaulstich@mn.ufrj.br) \\ ${ }^{2}$ Centro de Tecnologia Mineral - CETEM, Coordenação de Análises Minerais, Setor de Caracterização Tecnológica, \\ Rio de Janeiro, RJ, BR. \\ 3Universidade Federal do Rio de Janeiro - UFRJ, Instituto de Geociências, Programa de Pós-Graduação em Geologia, \\ Rio de Janeiro, RJ, BR (vmenezes92@gmail.com; sarahscgs@gmail.com)
}

Recebido em 2 de dezembro de 2019; aceito em 20 de julho de 2020

\begin{abstract}
Resumo
O estudo de minerais pesados representa uma importante ferramenta para a correlação entre pegmatitos, pois corpos espacialmente próximos e com mineralogia semelhante são normalmente interpretados como cogenéticos e provenientes de uma mesma fonte. Os minerais pesados dos pegmatitos intrusivos no ortognaisse Resende Costa foram descritos por estereomicroscopia, espectroscopia Raman, difratometria de raios X e a partir de imagens de elétrons retroespalhados em microscópio eletrônico de varredura. Esses se encontram mineralizados em minerais de Sn (cassiterita) e $\mathrm{Nb}$-Ta (grupo da columbita-euxenita), semelhantemente aos pegmatitos intrusivos no metagranitoide Ritápolis, enquanto os corpos intrusivos no ortognaisse Cassiterita só exibem minerais do grupo da microlita e não apresentam cassiterita. Um intercrescimento entre fases de $\mathrm{Nb}$-Ta-Ti se mostra determinante para caracterizar os pegmatitos intrusivos no ortognaisse Resende Costa e diferenciá-los dos corpos relacionados tanto ao metagranitoide quanto ao ortognaisse. Sugere-se a presença de pelo menos três gerações de corpos pegmatíticos na Província Pegmatítica de São João del Rei, sendo eles correlatos aos protólitos do ortognaisse Cassiterita, do ortognaisse Resende Costa e do metagranitoide Ritápolis.
\end{abstract}

Palavras-chave: Mineralogia; Cinturão Mineiro; Mineralização em Sn-Nb-Ta.

\begin{abstract}
The study of heavy minerals is an important tool for the correlation between pegmatites, as bodies with similar mineralogy and spatial correlation are usually interpreted as cogenetic, sharing the same source. The heavy minerals of pegmatites intrusive into Resende Costa orthogneiss were described by stereomicroscopy, Raman spectroscopy, X-ray diffraction and backscattered electron images from scanning electron microscopy. These pegmatites are mineralized in $\mathrm{Nb}-\mathrm{Ta}$ and $\mathrm{Sn}$, similar to the pegmatites intrusive into the Ritápolis metagranite. The pegmatites intrusive into the Cassiterita orthogneiss exhibit only minerals of the microlite group while cassiterite is not observed. An intergrowth between phases of $\mathrm{Nb}-\mathrm{Ta}-\mathrm{Ti}$ proves to be decisive to characterize the intrusive pegmatites in the Resende Costa orthogneiss and differentiate them from bodies related to both metagranitoids and orthogneiss. It is suggested the presence of at least three generations of pegmatitic bodies in the Pegmatitic Province of São João del Rei, being correlated to the protoliths of the Cassiterita orthogneiss, the Resende Costa orthogneiss and the Ritápolis metagranitoide.
\end{abstract}

Keywords: Mineralogy; Mineiro belt; Sn-Nb-Ta mineralization. 


\section{INTRODUÇÃO}

Os processos associados ao intemperismo podem ser considerados excelentes mecanismos para a decomposição química, a desagregação física e a transformação dos minerais dos diferentes tipos de rocha, principalmente os considerados mais instáveis, como os feldspatos, as micas e os anfibólios. Porém, certos minerais são mais resistentes ao intemperismo químico e, por isso, podem permanecer preservados em saprólitos rochosos, como o quartzo, a ilmenita, a cassiterita e o zircão, sendo designados resistatos. $\mathrm{O}$ estudo por diversas técnicas dos minerais resistentes ao intemperismo, principalmente aqueles com elevada densidade (comumente denominados minerais pesados), pode permitir uma compreensão mais aprofundada da paragênese dos litotipos. Uma das vantagens do estudo dos minerais pesados em relação aos minerais petrológicos está relacionada à facilidade de sua concentração por diversas técnicas gravíticas.

De maneira geral, os minerais pesados são utilizados na geologia para o estabelecimento de correlações estratigráficas (Pettijohn, 1941, 1975; Mange e Maurer, 1992), como indicadores da proveniência e de áreas-fonte de sedimentos (Mange e Morton, 2007; Krippner et al., 2016), para a caracterização da evolução das condições intempéricas de ambientes (Morton e Smale, 1990) e, principalmente, como rastreadores de mineralizações (Parfenoff et al., 1970; Pereira et al., 2005) e indicadores da presença de minerais de interesse econômico em corpos rochosos (Pereira et al., 2004, 2007). Na geologia econômica, ocupam papel extremamente relevante, uma vez que certos minerais pesados possuem importante valor econômico, como é o caso do diamante, do ouro, da cassiterita e de minerais do grupo da columbita-euxenita (Parfenoff et al., 1970; Pereira, 2012).

$\mathrm{O}$ estudo de minerais pesados se aplica diretamente no caso de pegmatitos, que são corpos rochosos constituídos quase que exclusivamente de quartzo, feldspato e mica, sendo que os minerais acessórios e/ou econômicos perfazem normalmente menos de $1 \%$ do total do corpo (London, 2008). Entre esses minerais se destacam a ilmenita, a cassiterita, a monazita, o xenotímio, o zircão e os do grupo da granada, da columbita-euxenita e do supergrupo da turmalina, que são normalmente minerais resistentes ao intemperismo químico e de densidade elevada, facilitando a concentração nos estudos de materiais saprolíticos.

No estado de Minas Gerais ocorrem duas grandes áreas com a presença abundante de pegmatitos, cujas gênese, mineralizações e idades são distintas. Essas são representadas pela Província Pegmatítica Oriental Brasileira - de idade neoproterozoica e mineralizada, principalmente, em berilo, turmalina e topázio (Correia Neves et al., 1986) - e pela Província Pegmatítica de São João del Rei - paleoproterozoica e com a presença abundante de minerais de Sn-Nb-Ta-Li (Quéméneur e Baraud, 1983; Pires e Porto Júnior, 1986; Pereira et al., 2003, 2008).
As rochas da Província Pegmatítica de São João del Rei se encontram fortemente alteradas pelo intemperismo químico, ocasionando a formação de espesso manto de intemperismo. De forma semelhante, os corpos pegmatíticos que cortam essas rochas também foram alterados pelo intemperismo, implicando, principalmente, na transformação do feldspato em argilominerais, como caulinita e halloysita. Durante o processo de concentração, alguns minerais, como o quartzo, o feldspato caulinizado e as micas, são eliminados em bateia, restando somente os minerais pesados. O presente trabalho teve como objetivo a caracterização mineralógica de diversos saprólitos de corpos pegmatíticos intrusivos no ortognaisse Resende Costa, comparando a súmula dos minerais pesados encontrada com aquela descrita nos demais corpos da Província Pegmatítica de São João del Rei, visando definir a relação entre eles.

\section{PROVÍNCIA PEGMATÍTICA DE SÃO JOÃO DEL REI}

A Província Pegmatítica de São João del Rei está localizada na porção centro-sul do Estado de Minas Gerais, abrange uma área de aproximadamente $2.700 \mathrm{~km}^{2}$ e foi descoberta por volta de 1940 (Coelho, 1942). É conhecida no cenário nacional pelos potentes corpos da área da mina da Volta Grande, onde são explotados espodumênio, feldspato, cassiterita, minerais do subgrupo da columbita e do grupo da microlita, bem como por diversos corpos menores, como Cascalho Preto, Socêgo, Fazenda Olaria, Paiol, Mato Virgem e Cavalo do Buraco (Francesconi, 1972), que foram garimpados para minerais de $\mathrm{Sn}-\mathrm{Ta}-\mathrm{Nb}$.

Vários trabalhos foram realizados envolvendo a caracterização mineralógica dos pegmatitos da Província Pegmatítica de São João del Rei (Rolff, 1947, 1948, 1951, 1952a, 1952b; Guimarães, 1950, 1956; Guimarães e Belezkij, 1956; Heinrich, 1964; Francesconi, 1972; Pereira et al., 2003, 2004, 2008; Faulstich, 2016; Faulstich et al., 2016; Alves, 2017; Alves et al., 2019; Cidade, 2019), assim como as fases evolutivas presentes (Pires e Porto Júnior, 1986; Quéméneur, 1987; Lagache e Quéméneur, 1997; Assumpção, 2015), porém sempre associando a gênese dos corpos pegmatíticos a um grande corpo granítico que aflora na região de entorno da cidade de Santa Rita - hoje Ritápolis - designado metagranitoide Ritápolis (Ávila, 2000).

Em relação ao contexto geológico, a Província Pegmatítica de São João del Rei está inserida na borda meridional do Cráton do São Francisco e encontra-se espacial e temporalmente associada à evolução geológica do Cinturão Mineiro (Figura 1), que corresponde à junção de quatro arcos magmáticos designados Cassiterita, Resende Costa, Serrinha e Ritápolis (Ávila, 2000; Ávila et al., 2010, 2014; Teixeira et al., 2015; Barbosa et al., 2019; Cardoso et al., 2019). Em geral, os pegmatitos dessa província são intrusivos em filitos e anfibolitos da sequência metavulcanossedimentar Rio das 


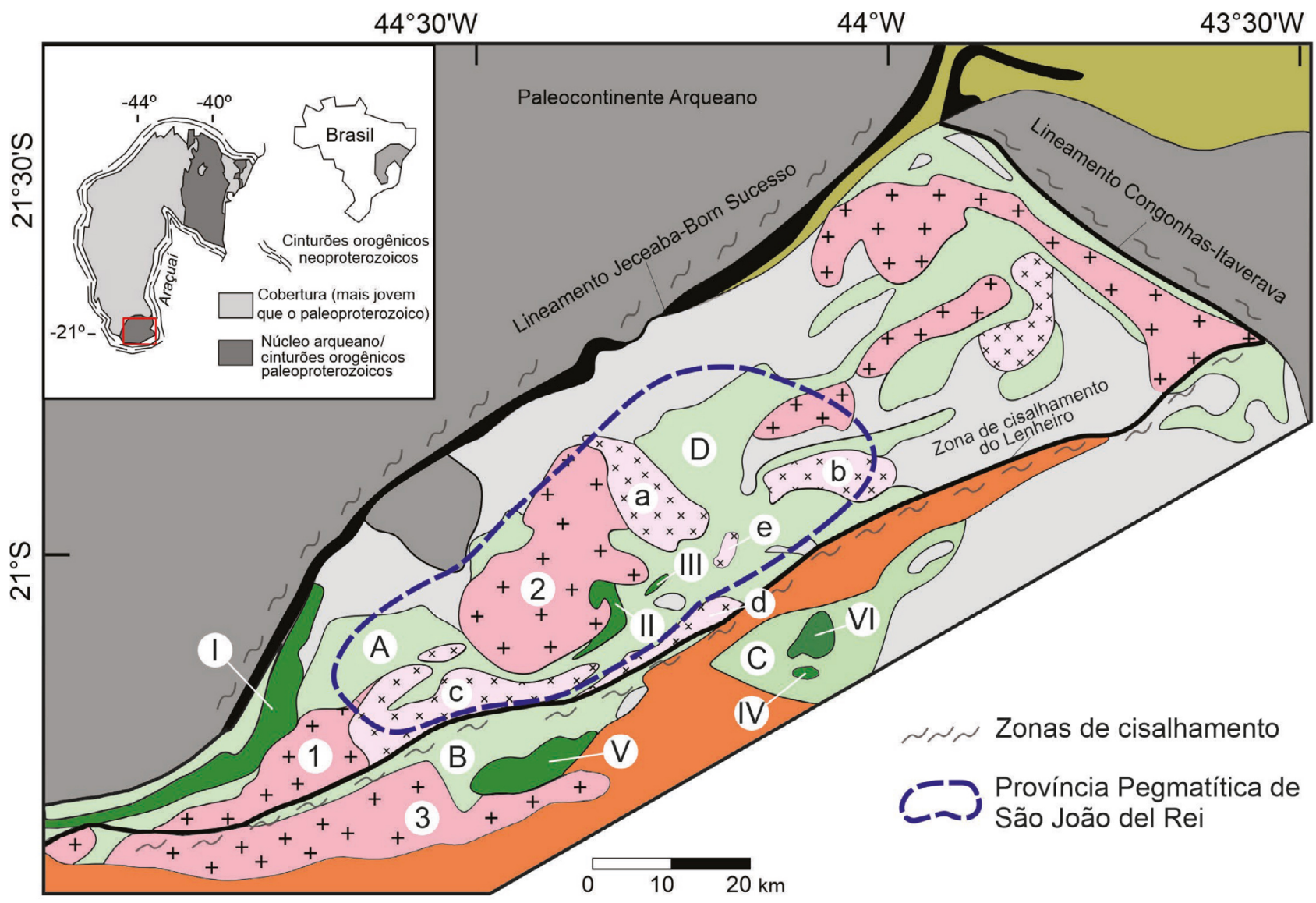

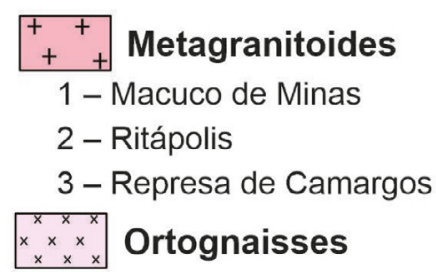

a - Resende Costa

b - Lagoa Dourada

c - Cassiterita

d - Fé

e - Ribeirão dos Mosquitos

\section{Sequências}

metavulcanossedimentares

A - Rio das Mortes

B - Nazareno

C - Dores de Campos

D - Restinga de Baixo

Metadioritos e metagabros

I - Metadiorito Rio Grande

II - Metadiorito Brumado

III - Metaquartzo-monzodiorito Glória

IV - Metaquartzo-diorito Dores de Campos

V - Metagabro São Sebastião da Vitória

VI - Metagabro Vitoriano Veloso

\section{Sucessões meso e neoproterozoicas}

\section{Supergrupo Minas}

Sequências metassedimentares clásticas e químicas/BIFs

\section{Paleocontinente}

Arqueano

Crosta não diferenciada

Fonte: modificado de Cardoso et al., 2019.

Figura 1. Geologia simplificada do Cinturão Mineiro envolvendo a distribuição dos metagranitoides, dos metadioritos, dos ortognaisses e das rochas das sequências metavulcanossedimentares Rio das Mortes, Nazareno, Dores de Campos e Restinga de Baixo.

Mortes e em ortognaisses, metagranitoides e metadioritos do Cinturão Mineiro, cujas idades variam do Sideriano ao Riaciano. Entre esses corpos podem ser destacados:

- os ortognaisses Cassiterita (2472 $\pm 11 \mathrm{Ma}$ - Barbosa et al., 2019), Resende Costa (2351 $\pm 48 \mathrm{Ma}$ - Teixeira et al., 2015), Fé (2191 $\pm 9 \mathrm{Ma}$ - Teixeira et al., 2008),
Glória (2189 \pm 29 Ma — Ávila et al., 2006) e Ribeirão dos Mosquitos (2146 $\pm 5 \mathrm{Ma}$ - Ávila et al., 2015);

- as rochas anfibolíticas das sequências metavulcanossedimentares Rio das Mortes (2231 \pm 5 a $2202 \pm 11 \mathrm{Ma}-$ Ávila et al., 2012) e Nazareno (2267 \pm 14 a $2223 \pm$ $4 \mathrm{Ma}$ - Ávila et al., 2012); 
- os metagabros São Sebastião da Vitória $(2220 \pm 3 \mathrm{Ma}$ — Valença et al., 2000) e Vitoriano Veloso (2193 \pm 12 a $2183 \pm 11 \mathrm{Ma}$ - Vieira, 2015) e os metadioritos Rio Grande (2128 \pm 24 a $2102 \pm 33 \mathrm{Ma}$ - Cardoso et al., 2019) e Brumado (2124 $\pm 6 \mathrm{Ma}$ - Cardoso et al., 2019); - os metagranitoides Ritápolis $(2149 \pm 10$ a $2121 \pm 7$ Ma - Ávila, 2000; Barbosa et al., 2015) e Macuco de Minas (2114 $\pm 6 \mathrm{Ma}$ - Barbosa et al., 2015).

Faulstich (2016) demonstrou que os corpos pegmatíticos dessa província variam em relação à mineralogia, à fonte e à idade, e aqueles intrusivos no ortognaisse Cassiterita não são mineralizados em cassiterita, gahnita e minerais do subgrupo da columbita e apresentam idade U-Pb LA-ICPMS de 2489 \pm 10 Ma. Já os corpos intrusivos nos filitos e nos anfibolitos da sequência metavulcanossedimentar Rio das Mortes, no metadiorito Brumado e no metagranitoide Ritápolis são mineralizados em cassiterita, gahnita e minerais do subgrupo da columbita, variando em idade de $2129 \pm 33$ a $2121 \pm 9 \mathrm{Ma}$ (Tabela 1). A partir desses dados, Faulstich (2016) sugeriu que a Província Pegmatítica de São João del Rei apresentaria pelo menos duas gerações de corpos pegmatíticos, que estariam relacionadas, respectivamente, ao ortognaisse Cassiterita, cuja idade de cristalização varia entre $2472 \pm 11$ e $2414 \pm 29 \mathrm{Ma}$ (Barbosa et al., 2019), e ao metagranitoide Ritápolis, de idade entre $2149 \pm 10 \mathrm{Ma}$ (Barbosa et al., 2015) e $2121 \pm 7$ Ma (Ávila, 2000). Segundo Faulstich et al. (2016), os pegmatitos presentes na região de Resende Costa - Lagoa Dourada fariam parte da Província Pegmatítica

Tabela 1. Rocha encaixante, idades e plútons fonte dos pegmatitos da Província Pegmatítica de São João del Rei.

\begin{tabular}{|c|c|c|c|}
\hline $\begin{array}{l}\text { Rocha } \\
\text { encaixante }\end{array}$ & $\begin{array}{c}\text { Idade em } \\
\text { zircão (Ma) }\end{array}$ & Método & $\begin{array}{c}\text { Plúton } \\
\text { fonte dos } \\
\text { pegmatitos }\end{array}$ \\
\hline $\begin{array}{l}\text { Metadiorito } \\
\text { Brumado }\end{array}$ & $2121 \pm 28^{\star}$ & LA-ICPMS & $\begin{array}{l}\text { Metagranitoide } \\
\text { Ritápolis }\end{array}$ \\
\hline $\begin{array}{l}\text { Metagranitoide } \\
\text { Ritápolis }\end{array}$ & $2121 \pm 9^{\star}$ & LA-ICPMS & $\begin{array}{l}\text { Metagranitoide } \\
\text { Ritápolis }\end{array}$ \\
\hline $\begin{array}{l}\text { Filitos da } \\
\text { SMVS-RM }\end{array}$ & - & - & $\begin{array}{l}\text { Metagranitoide } \\
\text { Ritápolis }\end{array}$ \\
\hline $\begin{array}{l}\text { Anfibolitos da } \\
\text { SMVS-RM }\end{array}$ & $2129 \pm 33^{\star}$ & LA-ICPMS & $\begin{array}{l}\text { Metagranitoide } \\
\text { Ritápolis }\end{array}$ \\
\hline $\begin{array}{l}\text { Ortognaisse } \\
\text { Cassiterita }\end{array}$ & $2489 \pm 10^{*}$ & LA-ICPMS & $\begin{array}{l}\text { Ortognaisse } \\
\text { Cassiterita }\end{array}$ \\
\hline $\begin{array}{l}\text { Anfibolitos da } \\
\text { SMVS-RM } \\
\text { (área da } \\
\text { mina da } \\
\text { Volta Grande) }\end{array}$ & $\begin{array}{c}2207 \pm \\
13^{\star \star}\end{array}$ & $\mathrm{Pb}-\mathrm{Pb}$ & $\begin{array}{c}\text { Metagranitoide } \\
\text { Ritápolis (?) }\end{array}$ \\
\hline
\end{tabular}

de São João del Rei e, nesse caso, estariam relacionados ao metagranitoide Ritápolis. No entanto, nenhum estudo mais detalhado foi desenvolvido nesses corpos, seja em relação à sua caracterização mineralógica, seja em relação à sua gênese.

\section{Ortognaisse Resende Costa}

O ortognaisse Resende Costa aflora por aproximadamente $65 \mathrm{~km}^{2}$ no entorno da cidade homônima (Figura 2) e é cortado por diversos pegmatitos que variam em espessura, desde centimétricos até métricos (Figura 3). Possui composição tonalítica, idade de cristalização entre $2351 \pm 48$ e $2317 \pm$ 16 Ma (Teixeira et al., 2015) e sua mineralogia essencial é representada por quartzo, plagioclásio e biotita, enquanto os minerais acessórios são zircão, apatita, allanita, titanita, ilmenita, magnetita, pirita, rutilo, microclínio, monazita, xenotímio, epidoto, clinozoisita/zoisita, sericita, carbonato e granada (Cidade, 2019). Columbita, microlita, cassiterita e turmalina são muito raros e foram identificados em somente alguns saprólitos desse corpo, enquanto "limonita", óxidos/hidróxidos de Mn e pirita limonitizada são fases tipicamente intempéricas e ocorrem em todos os saprólitos (Cidade, 2019).

\section{AMOSTRAGEM E MÉTODO DE ESTUDO}

\section{Amostragem, concentração e procedimento laboratorial}

Aproximadamente $25 \mathrm{~kg}$ de material saprolítico foram coletados de 16 diferentes corpos pegmatíticos intrusivos no ortognaisse Resende Costa (Tabela 2), e todas as amostras seguiram a rotina de preparação apresentada na Figura 4. Antes da coleta do material foi realizada uma limpeza superficial na área dos corpos amostrados, retirando-se com uma pá a parte superior do saprólito para que não ocorresse contaminação com solo residual (Figura 5A). Em seguida, o material foi deslamado em água corrente para a retirada da fração argilosa (Figura 5B) e peneirado a $2 \mathrm{~mm}$ (Figura 5C). $\mathrm{O}$ material mais grosso foi analisado macroscopicamente, catado (caso houvesse algum mineral de interesse) e posteriormente descartado, enquanto o material mais fino foi concentrado em bateia (Figura 5D). O objetivo do bateamento é fazer uma concentração inicial dos minerais pesados, tendo em vista que grande parte dos minerais mais leves, representados pelo quartzo, pelo feldspato e pelas micas, é eliminada durante esse processo.

Em laboratório, cada concentrado passou por um processamento em três etapas para limpeza, separação gravítica e classificação magnética (Figura 4). A primeira etapa foi realizada por meio de um banho ultrassônico para a retirada da argila residual e a liberação de crostas presentes ao redor dos grãos. A segunda etapa envolveu a utilização de 


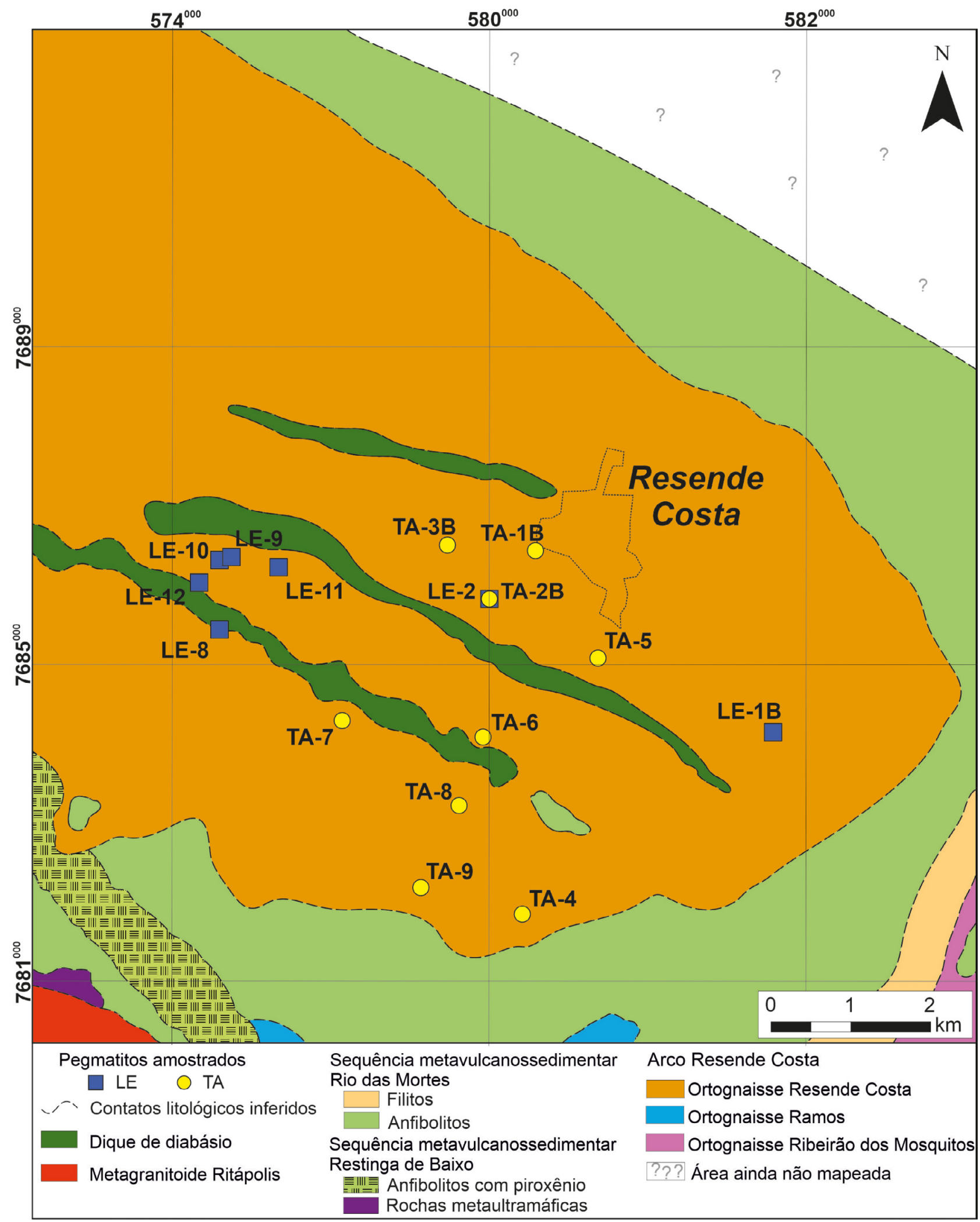

Fonte: Cidade (2019).

Figura 2. Mapa litológico da região de entorno da cidade de Resende Costa com pontos de coleta dos saprólitos dos pegmatitos intrusivos no ortognaisse Resende Costa. 

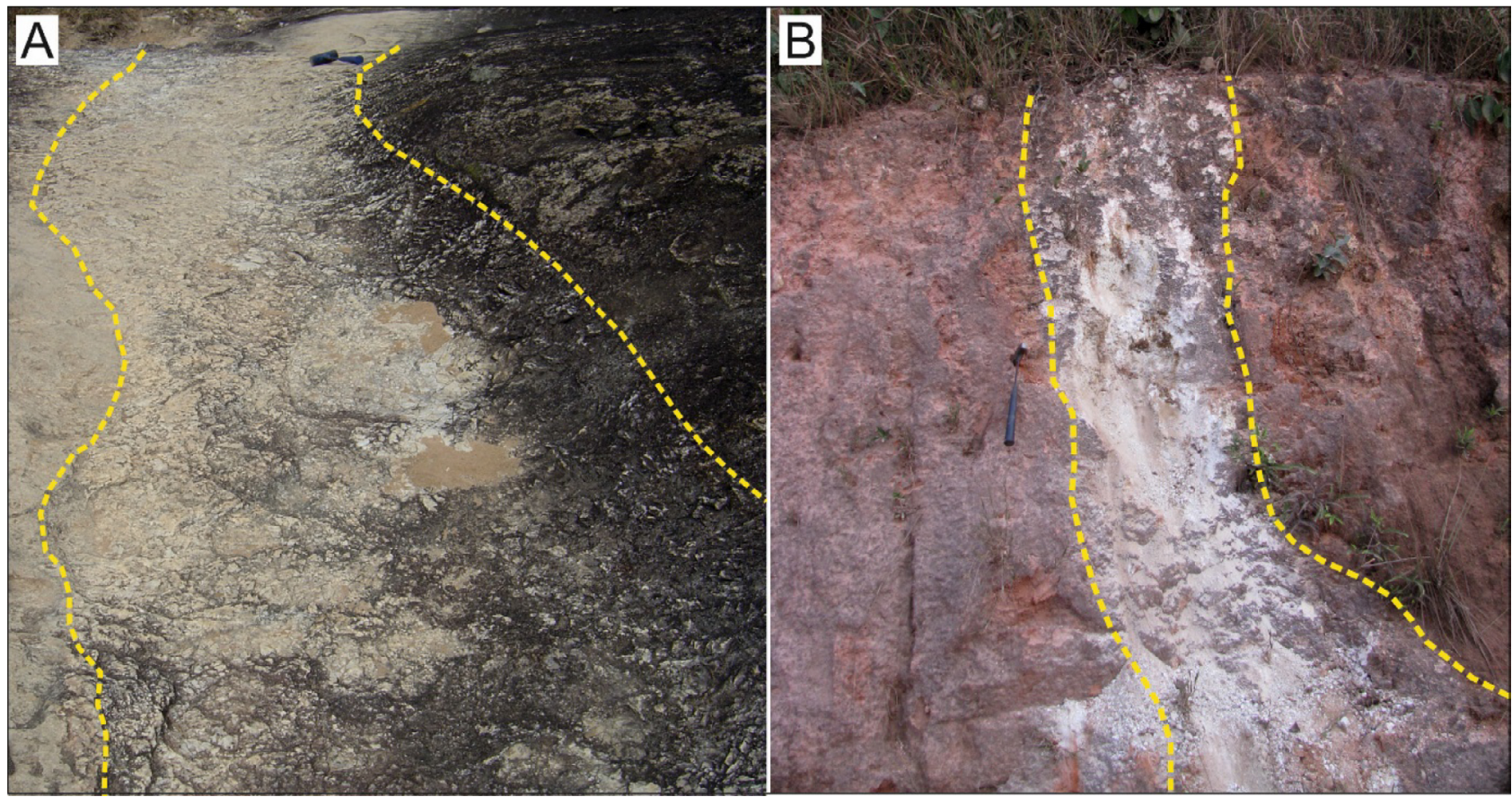

Figura 3. Exposições de pegmatitos intrusivos no ortognaisse Resende Costa: (A) pegmatito não alterado (tracejado amarelo) intrusivo no ortognaisse Resende Costa; (B) pegmatito alterado intempericamente (tracejado amarelo) associado ao saprólito do ortognaisse Resende Costa.

Tabela 2. Códigos e coordenadas (UTM, SIRGAS 2000, Zona 23S) dos pegmatitos amostrados. Localização dos corpos na Figura 2.

\begin{tabular}{lccccc}
\hline Código do ponto & Coordenada X & Coordenada Y & Código do ponto & Coordenada X & Coordenada Y \\
\hline LE-1B & 581524 & 7684135 & TA-2B & 577956 & 7685821 \\
LE-2 & 577956 & 7685807 & TA-3B & 577423 & 7686501 \\
LE-8 & 574553 & 7685437 & TA-4 & 578374 & 7681840 \\
LE-9 & 574553 & 7686303 & TA-5 & 579321 & 7685073 \\
LE-10 & 574691 & 7686346 & TA-6 & 577894 & 7884083 \\
LE-11 & 575291 & 7686222 & TA-7 & 576108 & 7684290 \\
LE-12 & 574294 & 7686024 & TA-8 & 577573 & 7683217 \\
TA-1B & 578536 & 7686419 & TA-9 & 577092 & 7682175 \\
\hline
\end{tabular}

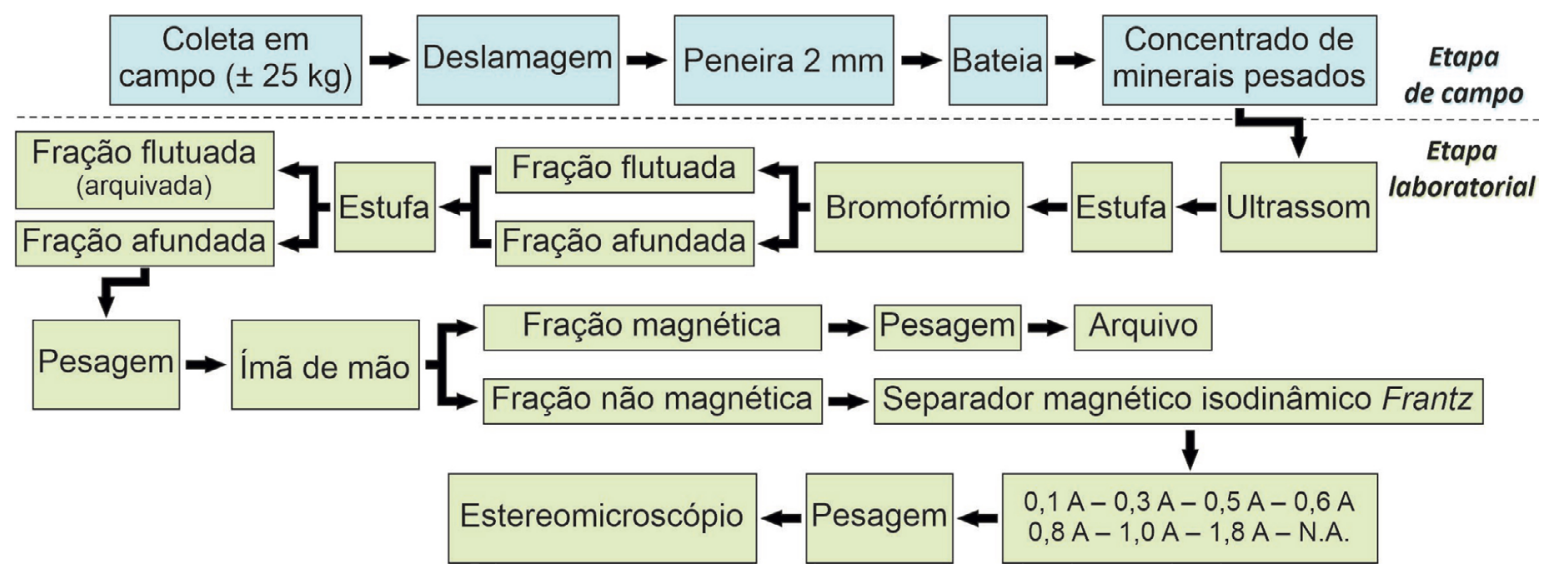

Figura 4. Fluxograma das etapas de preparação em campo e em laboratório dos concentrados de minerais pesados até a fase de estudo em estereomicroscópio. 


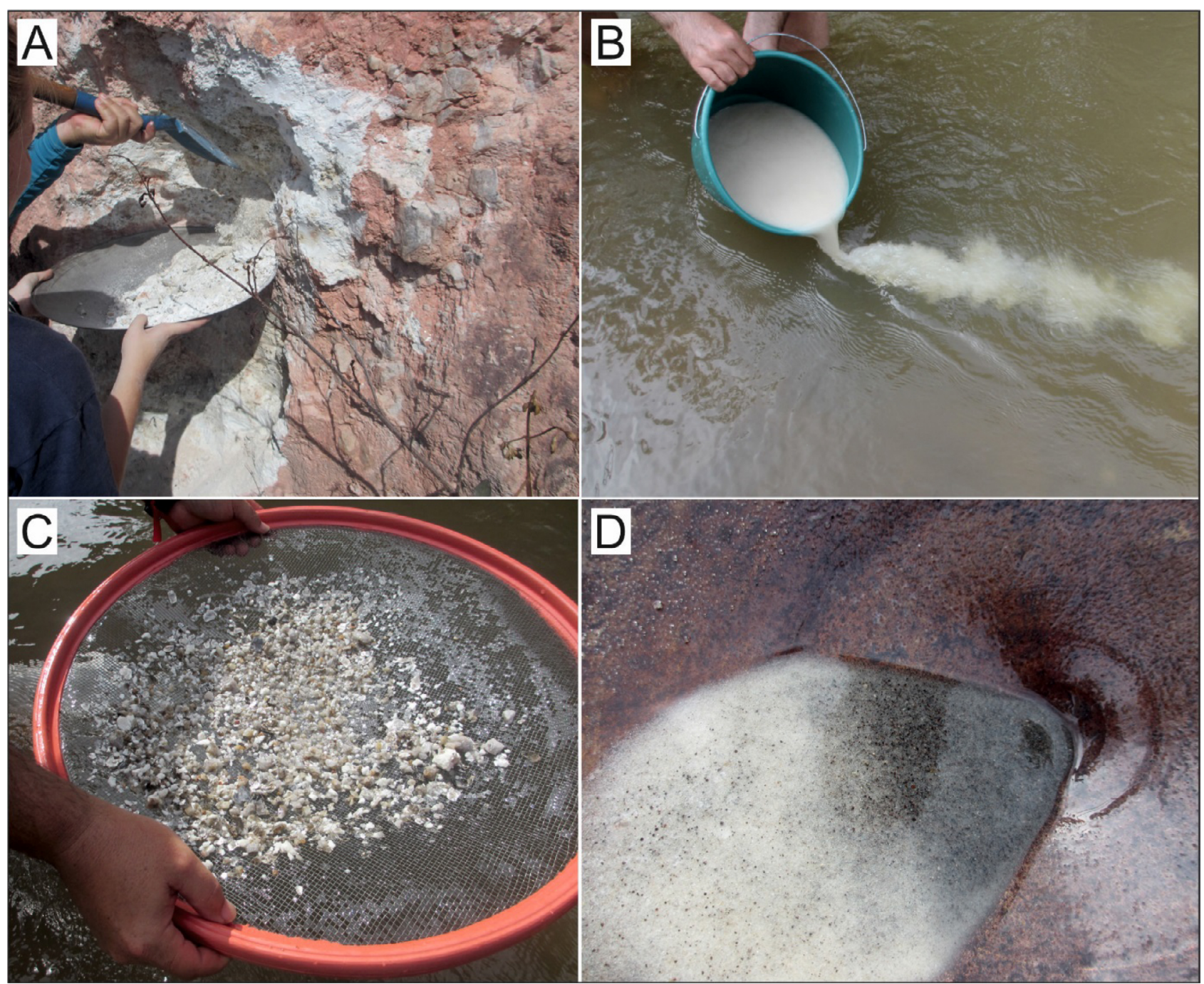

Figura 5. Fases de coleta e processamento em campo do material saprolítico oriundo de pegmatitos. (A) Coleta do saprólito do pegmatito após a limpeza do afloramento; (B) deslamagem do material saprolítico com a eliminação da argila e do silte em suspensão a partir da retirada da água turva; $(C)$ processo de peneiramento com a retenção do material mais grosso que $2 \mathrm{~mm}$; (D) concentração parcial dos minerais pesados em bateia.

bromofórmio como meio denso $(\mathrm{d}=2,89 \mathrm{~kg} / \mathrm{L})$ para retirada da fração leve, principalmente quartzo, feldspato e muscovita que não foram eliminados durante a concentração em bateia. Na terceira etapa foram utilizados ímã de ferrite e separador magnético isodinâmico Frantz em diferentes correntes para classificação dos minerais ferri-, para- e/ou diamagnéticos presentes nos concentrados.

\section{Métodos de análise}

Os produtos obtidos no separador magnético isodinâmico Frantz foram analisados por estereomicroscopia para identificação e caracterização dos minerais de acordo com suas principais características físicas. A quantificação do material foi realizada a partir da estimativa da porcentagem de cada um dos tipos de minerais encontrados no campo visual da amostra utilizando-se como referência a proposta de Terry e Chilingar (1955), em que cada produto do separador magnético isodinâmico Frantz foi pesado e teve sua mineralogia estimada em volume e depois convertida em \% massa. A espectroscopia Raman foi utilizada como técnica auxiliar na identificação qualitativa de minerais por meio da comparação dos espectros obtidos com o programa e o banco de dados mineralógico Crystal Sleuth (Lafuente et al., 2015). O equipamento utilizado foi uma microssonda Raman Horiba Jobin Yvon modelo LabRAM800 HR, equipada com um detector CCD refrigerado termoeletronicamente a $-70^{\circ} \mathrm{C}$ (efeito Peltier) e uma grade de difração de 1.800 linhas $/ \mathrm{mm}$, 
com resolução espectral de aproximadamente $0,5 \mathrm{~cm}^{-1} \mathrm{com}$ um microscópio petrográfico Olympus BX41 acoplado.

Análises por difratometria de raios X (DRX) foram desenvolvidas utilizando o método do pó em um equipamento Bruker-AXS D8 Advance Eco, radiação $\mathrm{Cu} \mathrm{K} \alpha$, $\lambda=0,154056 \mathrm{~nm}$, operado a $40 \mathrm{kV}$ e $25 \mathrm{~mA}$, de 5 a $70^{\circ} 2 \theta$ com passo de $0,02^{\circ} 2 \theta$, tempo de contagem de 184 segundos por passo com detector linear sensível à posição do tipo silicon drift com discriminação de energia LynxEye $\mathrm{XE}, \mathrm{e}$ em geometria $\Theta-\Theta$ do goniômetro. As interpretações qualitativas de espectro de raios $\mathrm{X}$ foram efetuadas por comparação com padrões contidos no banco de dados PDF-04 (ICDD, 2020) em software Bruker-AXS Diffrac Eva 4.1.

Análises químicas qualitativas e imagens de elétrons retroespalhados foram obtidas em microscópios eletrônicos de varreduras Hitachi modelo TM 3030 Plus com espectrômetro de dispersão de energia Bruker Nano Analytics Quantax 70, ou FEI Quanta 400 com espectrômetro de fluorescência de raios X por dispersão de energia Bruker Nano Analytics Quantax 800, ambos sob tensão de aceleração de elétrons de $15 \mathrm{kV}$.

\section{RESULTADOS}

Os concentrados de minerais pesados dos pegmatitos intrusivos no ortognaisse Resende Costa são constituídos de grande gama de minerais, destacando-se a presença de grãos de granada com composição média entre almandina e spessartina, ilmenita, columbita-( $\mathrm{Fe})$, monazita-(Ce), cassiterita e zircão em todos os corpos estudados, enquanto xenotímio-(Y), gahnita, epidoto, minerais do grupo da microlita e do pirocloro, do supergrupo da turmalina, muscovita e hematita ocorrem somente em parte dos pegmatitos (Figura 6). Biotita, calcita, clinozoisita e rutilo foram encontrados como traço em alguns dos concentrados, enquanto limonita, pirita limonitizada e

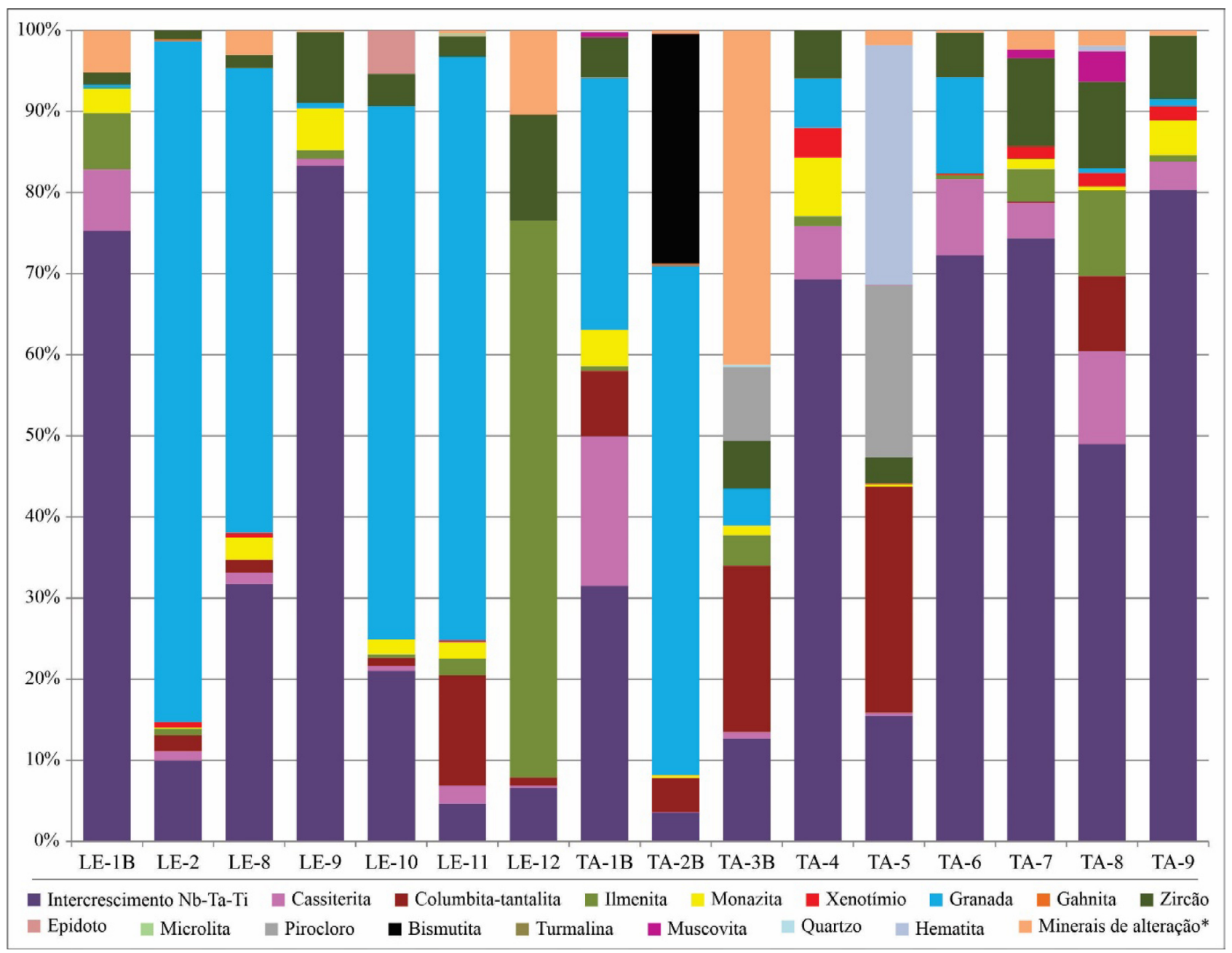

*Fases de alteração incluem: "limonita", pirita limonitizada e óxidos/hidróxidos de Mn.

Figura 6. Proporção dos minerais pesados presentes nos saprólitos dos corpos pegmatíticos intrusivos no ortognaisse Resende Costa (\% massa). 
óxidos/hidróxidos de Mn são produtos da alteração intempérica de minerais primários, pois, como dito anteriormente, os corpos amostrados estão fortemente alterados.

Thortveitita $\left[(\mathrm{Sc}, \mathrm{Y})_{2} \mathrm{Si}_{2} \mathrm{O}_{7}\right]$, torita $\left[(\mathrm{Th}, \mathrm{U}) \mathrm{SiO}_{4}\right]$, minerais do supergrupo da turmalina e dos grupos da microlita e do pirocloro foram identificados por espectroscopia Raman, enquanto bismutita $\left[\mathrm{Bi}_{2}\left(\mathrm{CO}_{3}\right) \mathrm{O}_{2}\right]$ e galena $(\mathrm{PbS})$ foram descritos pela primeira vez nos pegmatitos da Província Pegmatítica de São João del Rei, assim como um intercrescimento fino de minerais de $\mathrm{Nb}$-Ta-Ti cuja genêse ainda não está completamente compreendida (Figura 6).

\section{Grupo da granada $\left[\mathrm{A}_{3} \mathrm{~B}_{2}\left(\mathrm{SiO}_{4}\right)_{3}\right]$}

Minerais do grupo da granada são predominantes nos concentrados LE-2, LE-8, LE-10, LE-11 e TA-2B, enquanto nos demais variam de comuns (ocorrendo em proporção inferior a $30 \%$ ) a raros. São translúcidos e predominam grãos de cor laranja (Figura 7A), mas podem ser encontrados grãos incolores (Figura 7B) e raros cristais de coloração rosa (amostras TA-4, LE-9 e LE-10). Os concentrados LE-10 e TA-5 apresentam grãos laranja com duas tonalidades distintas, sendo uma mais clara e outra mais escura (Figura 7C). Quando fortemente alterados exibem capa de alteração preta em partes do grão (Figura 7D). Podem apresentar forma dodecaédrica (Figura 7E) ou trapezoédrica (Figura 7F) e variam de euédricos a anédricos (Figura 7G).

Composicionalmente, a granada varia entre spessartina $(45,44-93,1 \%)$, almandina $(3,2-47,4 \%)$, grossulária $(0-34,3 \%)$, piropo $(0-4 \%)$ e andradita $(0,1-3,7 \%)$. No diagrama ternário almandina-spessartina-grossulária (Figura 8) é possível observar que os grãos de coloração laranja apresentam composição intermediária entre os membros ricos em $\mathrm{Mn}$ e Fe (spessartina e almandina, respectivamente), enquanto os grãos incolores exibem enriquecimento no membro final grossulária (rico em $\mathrm{Ca}$ ).

\section{Cassiterita $\left(\mathrm{SnO}_{2}\right)$}

A cassiterita é observada em proporção acima de 5\% nos concentrados LE-1B, TA-1B, TA-4, TA-6 e TA-8, enquanto nos demais corpos ocorre desde traço até $4,4 \%$. Varia de translúcida a opaca, de adamantina a vítrea, de anédrica (Figura 9A) a euédrica (Figura 9B), ocorre em grãos tetragonais e pode

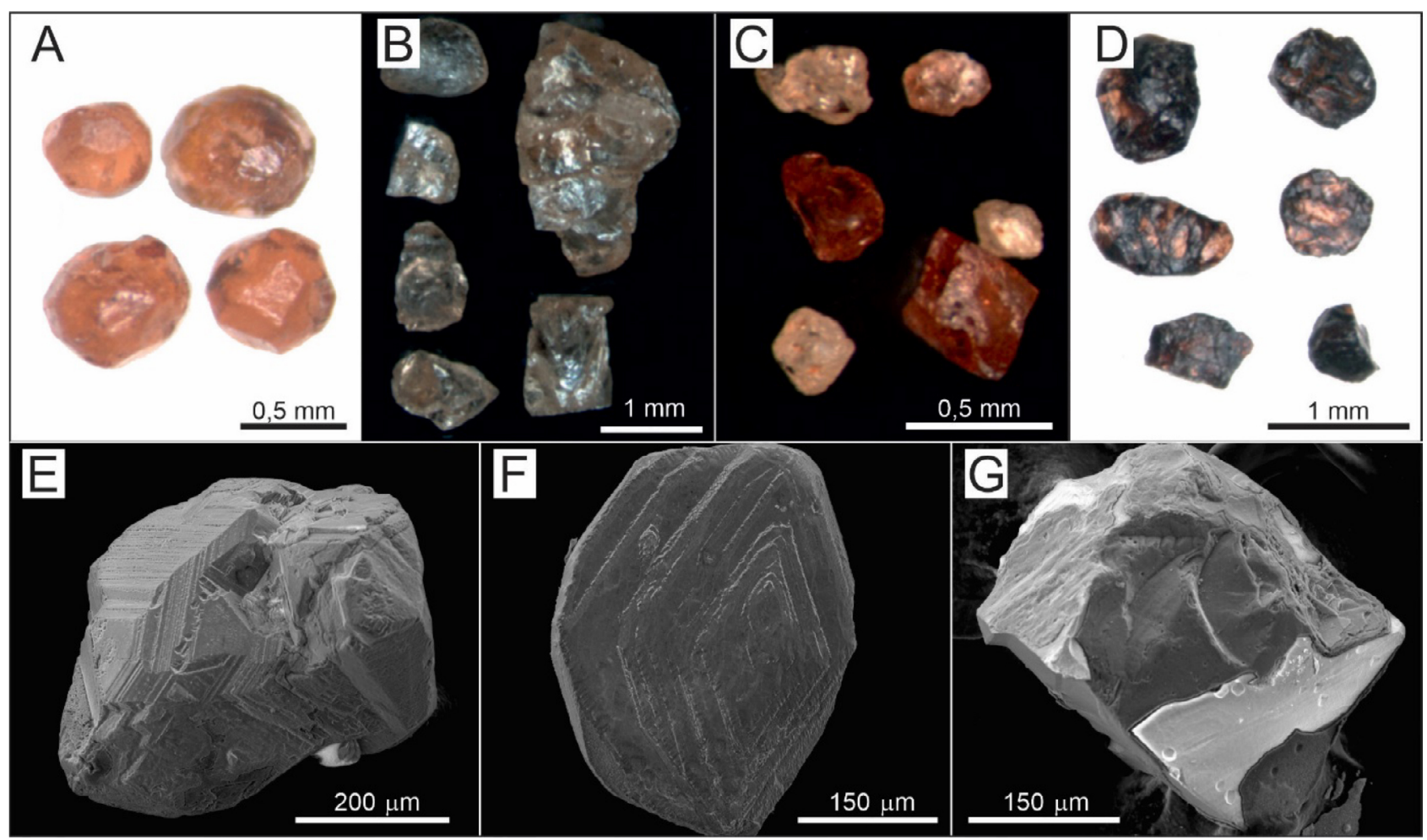

Figura 7. Granada dos pegmatitos intrusivos no ortognaisse Resende Costa. (A) Grãos de cor laranja dodecaédricos do corpo TA-1B; (B) grãos incolores anédricos do corpo TA-4; (C) grãos de cor laranja variando de claro a escuro. Amostra do corpo TA-5; (D) grãos parcialmente limonitizados (porções pretas). Amostra do corpo LE-11; (E) imagem de elétrons retroespalhados da face de um grão de granada com forma dodecaédrica. Amostra do corpo TA-7; (F) imagem de elétrons retroespalhados de grão de granada com forma trapezoédrica. Amostra do corpo TA-7; (G) imagem de elétrons retroespalhados de grão de granada anédrico e fortemente fraturado. Amostra do corpo TA-9. 


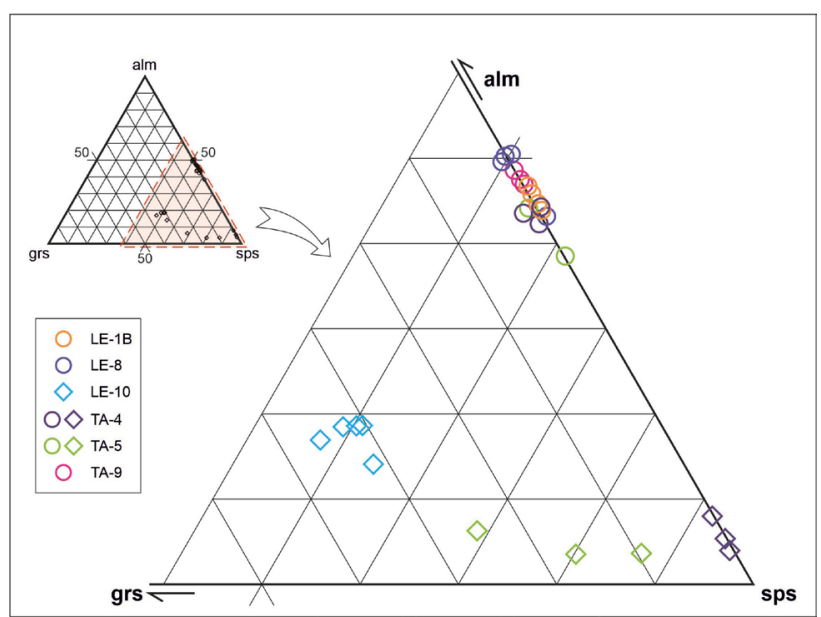

Figura 8. Diagrama ternário de granada com os membros finais almandina (alm) - grossulária (grs) - spessartina (sps). Pontos marcados como círculos representam grãos de tonalidade laranja e rosa e os losangos, grãos incolores. alcançar tamanho máximo de $2 \mathrm{~mm}$. Possui cor castanha a avermelhada e encontra-se comumente associada ao intercrescimento de fases de Nb-Ta-Ti (Figuras 9C e 9D).

\section{Intercrescimento de fases de $\mathrm{Nb}-\mathrm{Ta}-\mathrm{Ti}$}

$\mathrm{O}$ material formado pelo intercrescimento de fases de $\mathrm{Nb}$-Ta-Ti ocorre em todos os concentrados estudados, perfazendo normalmente $30 \%$ ou mais em massa (Figura 6), sendo as únicas exceções os pontos LE-2, LE-11, LE-12 e TA-2B, nos quais representa entre 1 e 5\%. O intercrescimento é opaco, varia de preto a cinza-escuro (Figura 10A), de submetálico a terroso e pode apresentar massa branca ou amarela na sua superfície (Figura 10B), que está relacionada à alteração da fase rica em Ti. Varia amplamente em tamanho, alcançando até $5 \mathrm{~mm}$, assim como em relação à forma, sendo possível observar grãos anédricos, subédricos, arredondados (parecidos com a granada), tabulares (semelhantes à columbita) e
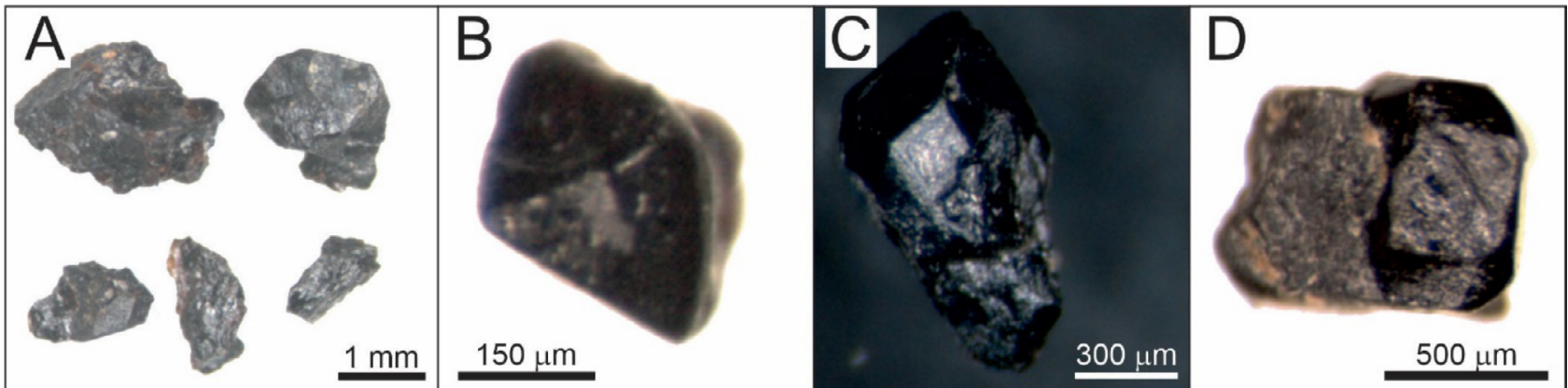

Figura 9. Cassiterita dos pegmatitos intrusivos no ortognaisse Resende Costa. (A) Grãos anédricos com tamanho máximo de 2 mm. Amostra do corpo TA-1B; (B) grão euédrico piramidal. Amostra do corpo TA-9; (C) grão euédrico com brilho adamantino em associação com o intercrescimento de fases de Nb-Ta-Ti. Amostra do corpo LE-11; (D) grão euédrico com brilho adamantino em associação com grão subédrico do intercrescimento de fases de Nb-Ta-Ti. Amostra do corpo TA-4.

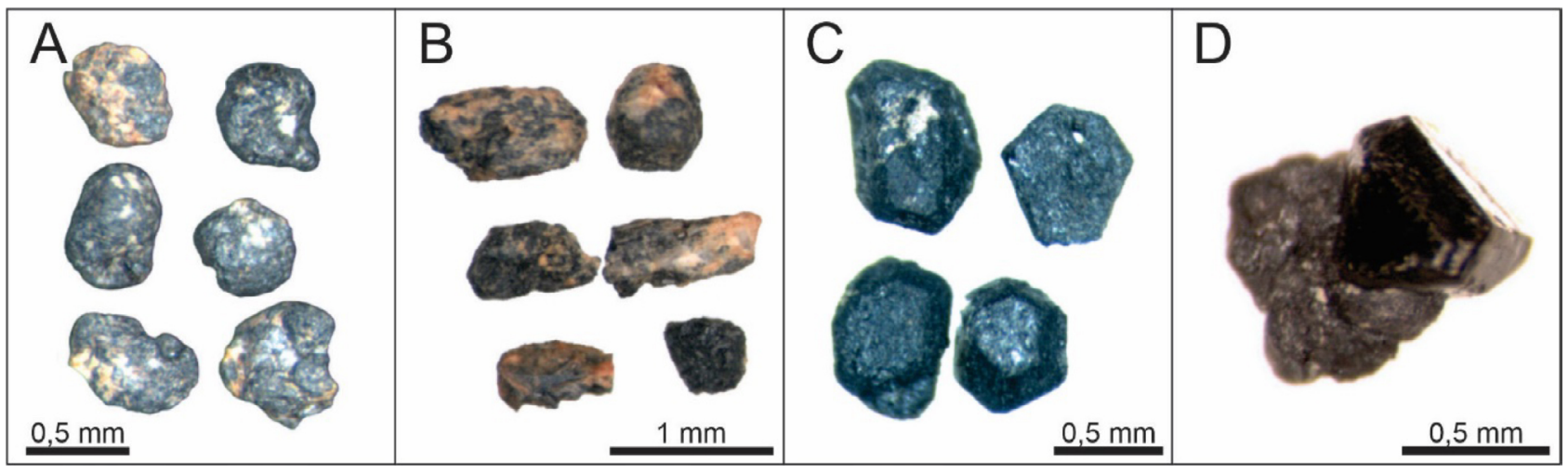

Figura 10. Intercrescimento de fases de Nb-Ta-Ti encontrado nos pegmatitos intrusivos no ortognaisse Resende Costa. (A) Grãos arredondados e anédricos com coloração preta acinzentada. Amostra do corpo LE-9; (B) grãos subédricos alongados e/ou tabulares com forma semelhante à dos minerais do grupo da columbita, com presença de alteração branca na superfície. Amostra do corpo LE-11; (C) grãos euédricos com forma dodecaédrica parecida com a granada. Amostra do corpo TA-4; (D) material composto do intercrescimento de fases de $\mathrm{Nb}$-Ta-Ti com forma anédrica em associação com grão de cassiterita castanha e euédrica. Amostra do corpo TA-7. 
cúbicos (Figuras 10A, 10B e 10C). Ocorre normalmente em paragênese com a cassiterita formando massas de grãos em que a forma pode variar amplamente (Figuras 9C, 9D, 10D e 11).

Por meio de microscopia eletrônica de varredura com análises por espectroscopia por energia dispersiva (MEV-EDS) foi possível constatar que o intercrescimento de fases de $\mathrm{Nb}$-Ta-Ti, além de apresentar inclusões e associação com cassiterita (Figura 10A), é formado por uma mistura de pelo menos três minerais: ilmenita, rutilo niobífero e columbita (Figura 11B). Geralmente as lamelas de cada uma das fases presentes são menores do que a resolução espacial das análises químicas por espectroscopia por energia dispersiva (EDS) ou por meio de ablação a laser, o que impossibilita identificação mais detalhada pelas técnicas utilizadas no presente trabalho.

Destaca-se que grãos com esse tipo de intercrescimento não foram descritos em nenhum dos trabalhos mineralógicos de maior detalhe realizados nos pegmatitos da Província Pegmatítica de São João del Rei (Rolff, 1947, 1948; Francesconi, 1972; Pires e Porto Júnior, 1986; Pereira et al., 2003, 2004, 2008; Faulstich, 2016) e no pegmatito da Volta Grande (Guimarães, 1950, 1956; Guimarães e Belezkij, 1956; Heinrich, 1964; Quéméneur, 1987; Lagache e Quéméneur, 1997; Assumpção, 2015; Alves, 2017).

\section{Bismutita $\left[\mathrm{Bi}_{2}\left(\mathrm{CO}_{3}\right) \mathrm{O}_{2}\right]$}

A bismutita ocorre como um dos principais minerais pesados no concentrado TA-2B e como traço nos pontos LE-8, TA-3B e TA-5, tendo sido caracterizada por espectroscopia Raman e difratometria de raios X (Figura 12). É translúcida, tem brilho resinoso e exibe diversas cores, entre as quais verde, preto, marrom ou branco, podendo ser bicolor. É observada em grãos anédricos com faces irregulares, normalmente alongados ou fibrosos (Figuras 13A, 13B e 13C) e, mais raramente, tabulares (Figura 13D). Segundo Dias e Wilson (2000), a bismutita pode ocorrer de forma natural ou como produto de alteração de bismuto nativo ou da bismutinita (sulfeto de bismuto) em pegmatitos. Esse mineral está sendo descrito pela primeira vez em corpos pegmatíticos da Província Pegmatítica de São João del Rei. Picos referentes a traços de muscovita, zircão e quartzo foram identificados por DRX.

\section{Galena (PbS)}

A galena ocorre como traço no concentrado TA-1B e corresponde à primeira descrição desse mineral nos pegmatitos da Província Pegmatítica de São João del Rei. É opaca, possui cor cinza-chumbo, brilho metálico, forma cúbica $\mathrm{e}$ clivagem bem definida nas três direções (Figura 14). Galena foi encontrada anteriormente na região em um concentrado de bateia de uma drenagem próxima ao pegmatito da Volta Grande (Santos e Pereira, 1983), em veios de quartzo associados ao ortognaisse Cassiterita (Pereira et al., 1998) e em veios sulfetados que cortam o metagranitoide Ritápolis (Ávila, 2000).

\section{Columbita-(Fe) $\left[(\mathrm{Fe}, \mathrm{Mn})(\mathrm{Nb}, \mathrm{Ta})_{2} \mathrm{O}_{6}\right]$}

A columbita- $(\mathrm{Fe})$ ocorre em quase todas as amostras variando de um mineral comum até raro — somente não
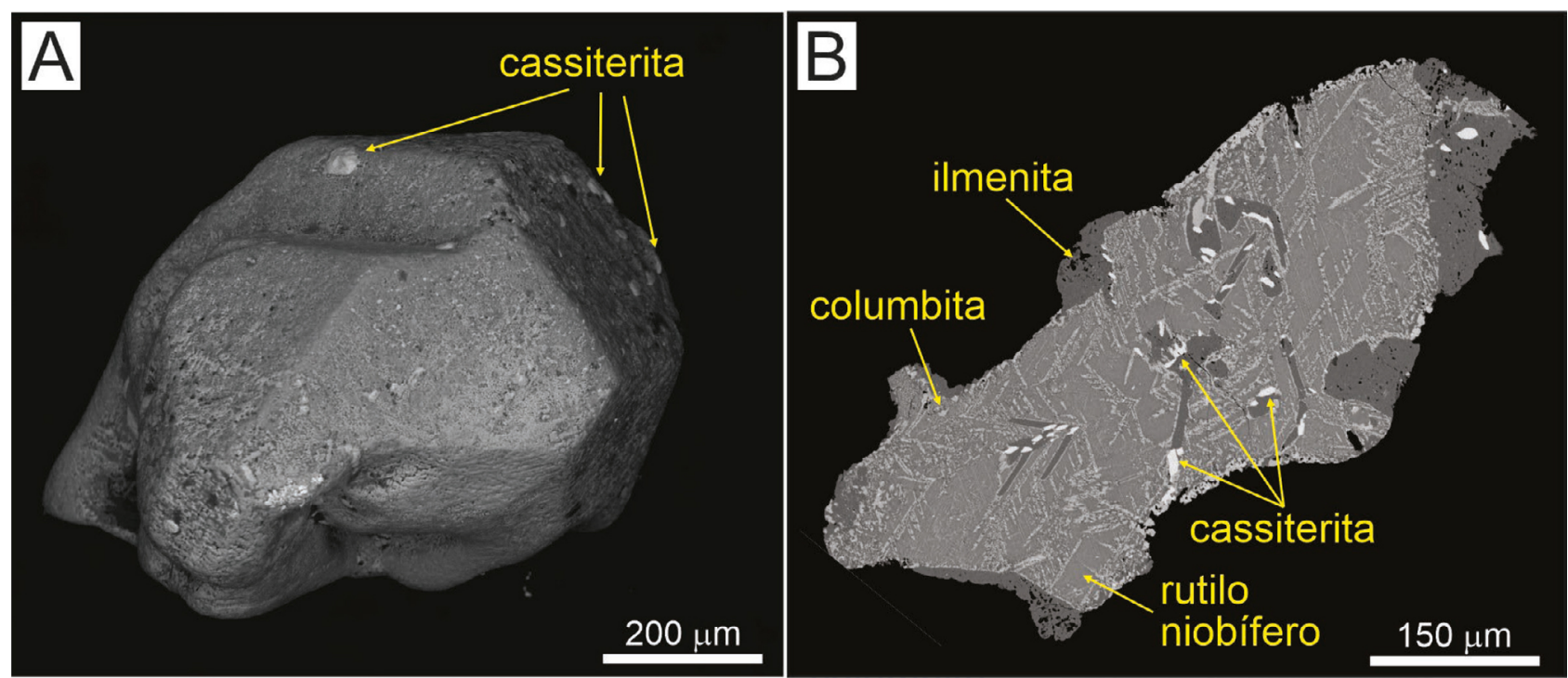

Figura 11. Imagens de microscopia eletrônica de varredura de grãos com o intercrescimento de fases de $\mathrm{Nb}$-Ta-Ti encontrados em pegmatitos da região de Resende Costa. (A) Imagem de elétrons secundários de grão euédrico do intercrescimento de fases de $\mathrm{Nb}$-Ta-Ti em associação com pequenos grãos de cassiterita; (B) imagem de elétrons retroespalhados, em que é possível observar a distribuição das diferentes fases minerais presentes no intercrescimento $\mathrm{Nb}-\mathrm{Ta}-\mathrm{Ti}$. 


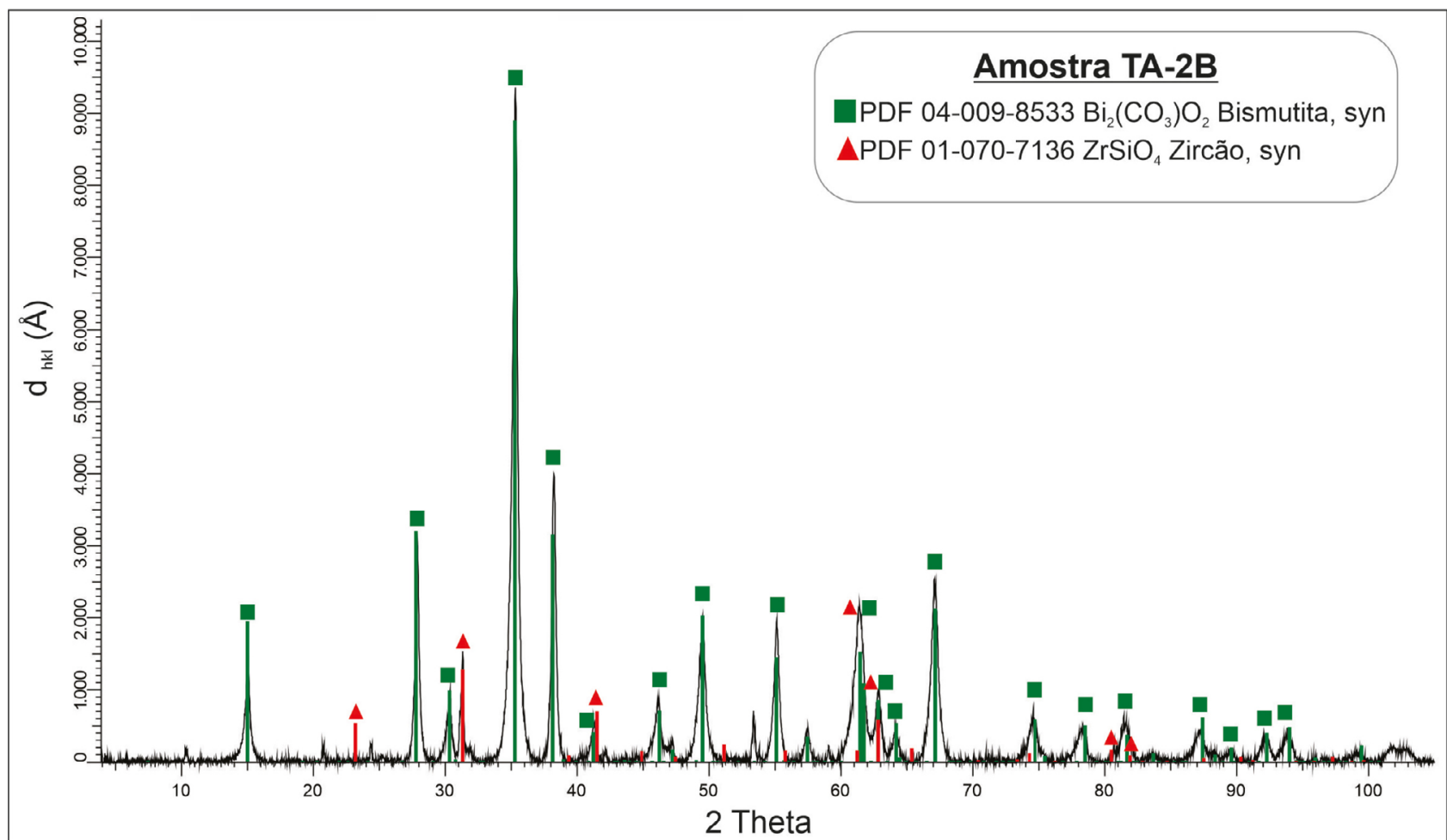

Figura 12. Difratograma de raios $X$ de grãos de bismutita com inclusões/associações com zircão da amostra TA-2B (background subtraído).
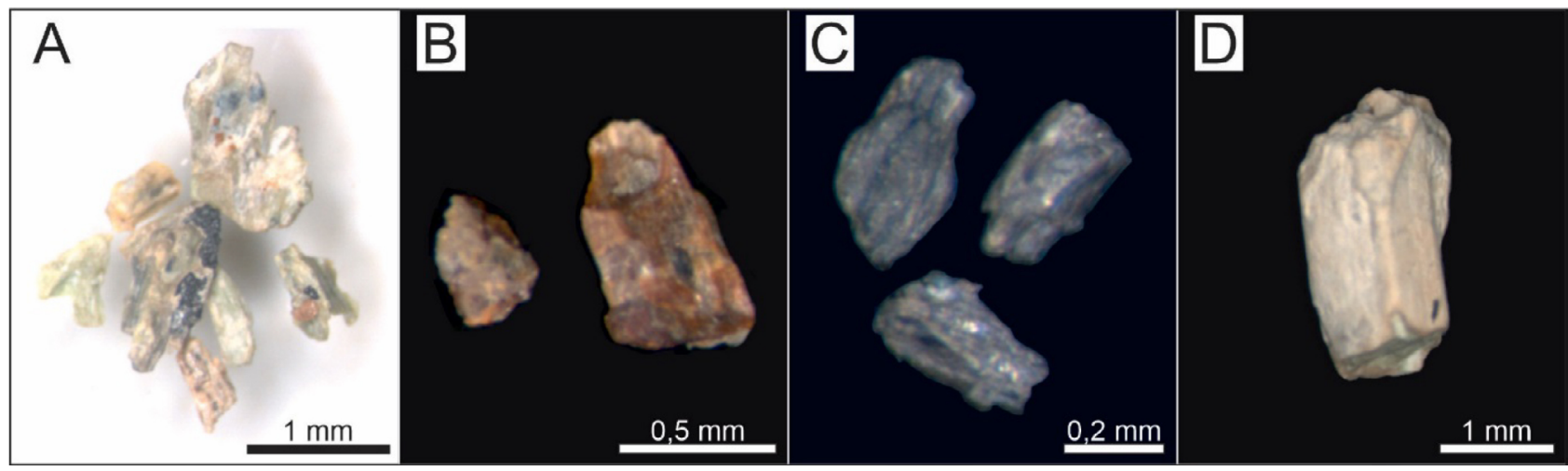

Figura 13. Bismutita do pegmatito TA-2B intrusivo no ortognaisse Resende Costa. (A) Grãos bicolores, alongados e fibrosos; (B) grãos castanhos e anédricos; (C) cristais pretos alongados; (D) cristal branco com formato tabular.

foi identificado na amostra LE-9. Os grãos de columbita- $(\mathrm{Fe})$ são pretos, apresentam brilho metálico, fraturas irregulares e faces alteradas. É comum a presença de fragmentos de grãos tabulares achatados de formato retangular (Figura 15A), comumente apresentando terminações em ponta de flecha (Figuras 15B e 15C) ou grãos anédricos (Figura 15D). Geralmente estão associados a uma massa branca ou amarela que mascara seu brilho e sua cor original (Figura 15C), correspondendo, na maioria das vezes, a pirocloro- $(\mathrm{Pb})$ ou microlita- $(\mathrm{Pb})$.

\section{Ilmenita $\left(\mathrm{FeTiO}_{3}\right)$}

A ilmenita está presente em todos os corpos estudados, e nos pegmatitos LE-12 e TA-8 perfaz, respectivamente, cerca de 70 e $10 \%$ dos minerais pesados, enquanto nas demais amostras ocorre em proporção inferior a 7\%. É metálica, preta a acinzentada, predominantemente anédrica (Figura 16A) e apresenta forma tabular achatada (Figura 16B). Pode estar alterada intempericamente com o desenvolvimento de uma fina capa esbranquiçada e/ou amarelada em sua superfície 


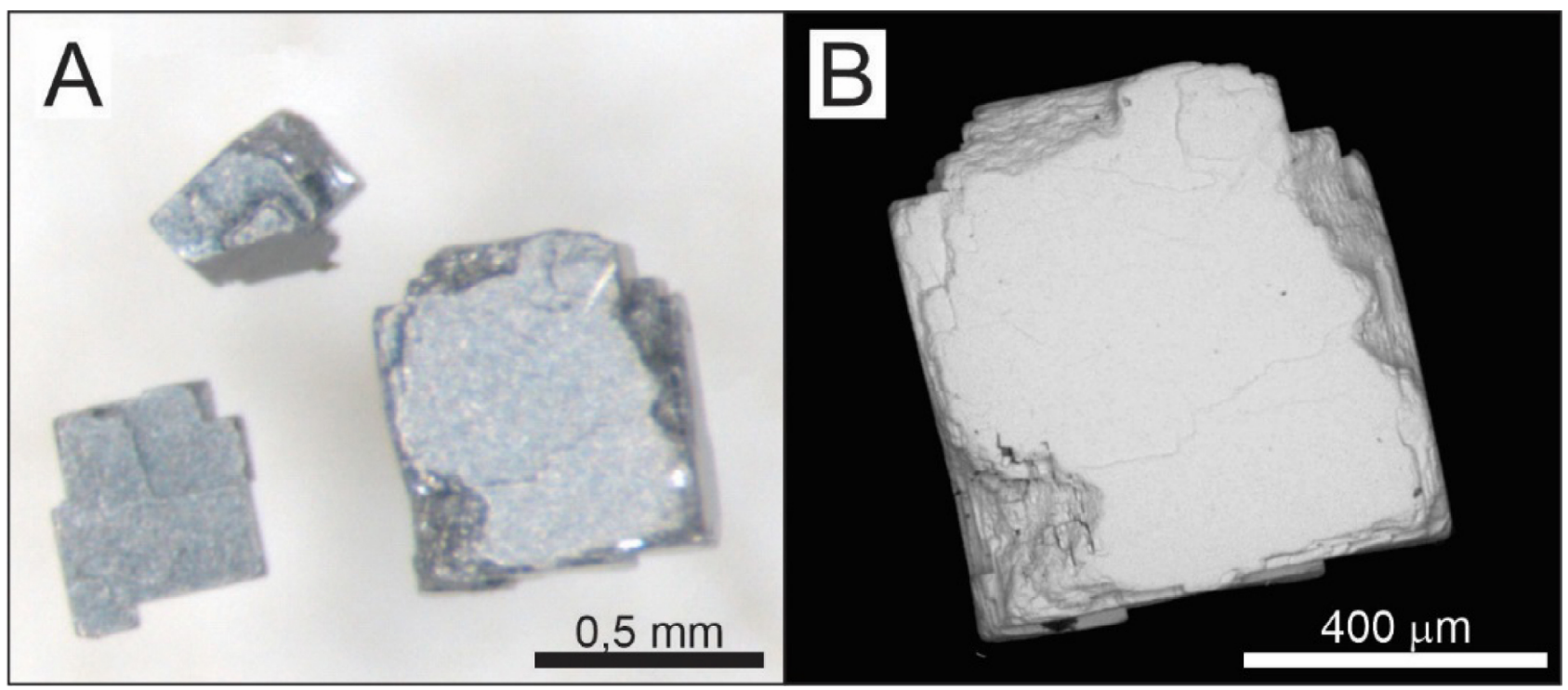

Figura 14. Galena do pegmatito TA-1B intrusivo no ortognaisse Resende Costa. (A) Foto em estereomicroscópio; (B) imagem de elétrons retroespalhados gerada em microscópio eletrônico de varredura a baixo vácuo.

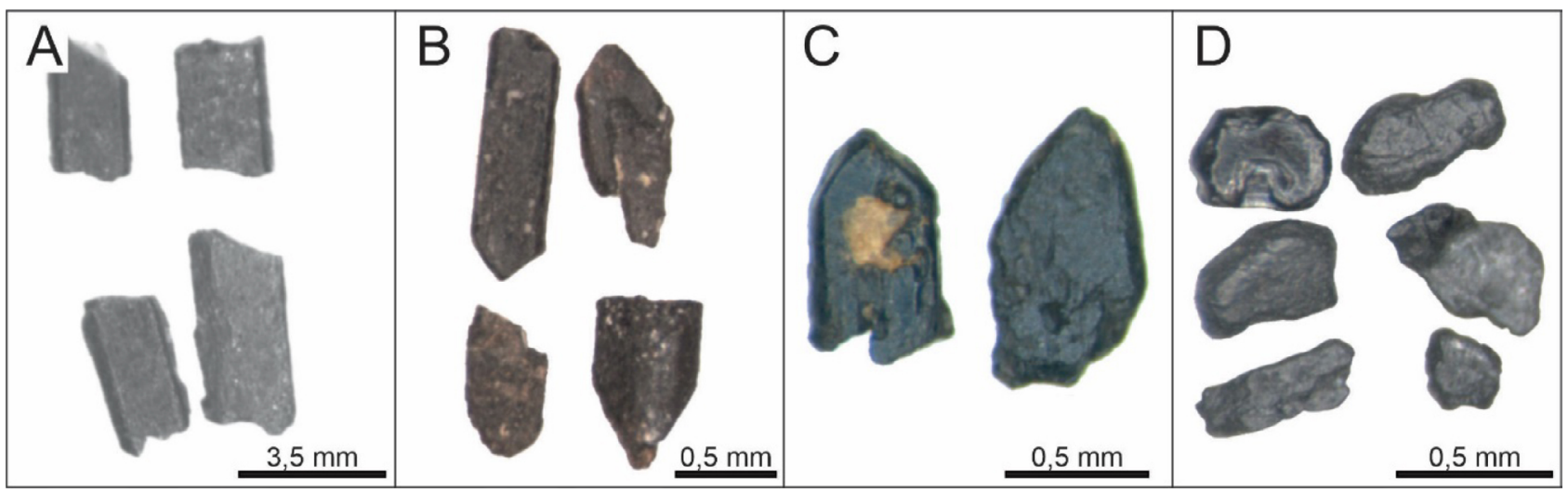

Figura 15. Columbita-(Fe) dos pegmatitos intrusivos no ortognaisse Resende Costa. (A) Grãos subédricos, alongados e tabulares. Amostra do corpo TA-3B; (B) grãos euédricos, alongados, tabulares e com terminação em ponta de flecha. Amostra do corpo TA-8; (C) grãos subédricos com terminação em ponta de flecha e com alteração superficial amarela. Amostra do corpo LE-8; (D) grãos anédricos. Amostra do corpo LE-12.

(Figura 16C), que corresponde a um óxido de Ti. Outra alteração muito comum na ilmenita é a presença de manchas avermelhadas (Figura 16D), que estão associadas ao processo de oxidação do $\mathrm{Fe}^{+2}$ para $\mathrm{Fe}^{+3}$.

\section{Monazita-(Ce) [(Ce,La,Nd,Th)PO $]$}

A monazita-(Ce) está presente em todos os concentrados, mas é observada em concentrações acima de 5\% somente nos pontos LE-9 e TA-4. Varia de transparente a translúcida, possui brilho desde vítreo (Figura 17A) até resinoso (Figuras 17B e 17C), cor amarela a esbranquiçada e frequentemente exibe uma capa de alteração branca com aspecto sacaroidal (Figura 17D). É encontrada sob a forma de prismas tabulares achatados, sendo predominantemente subédrica (Figuras 17A, 17B e 17C), com parte das faces preservada. Os cristais transparentes e com brilho vítreo são raros e só foram encontrados nas amostras LE-1B, TA-4, TA-5 e TA-7.

\section{Xenotímio-(Y) [YPO $]$}

O xenotímio-(Y) ocorre como mineral traço na maioria dos corpos e não foi identificado somente nas amostras LE-9 e LE-10. É observado em grãos euédricos bipiramidais com base quadrática (Figuras 18A e 18B) e anédricos, varia de transparente a translúcido, possui brilho desde vítreo (Figura 18A) 


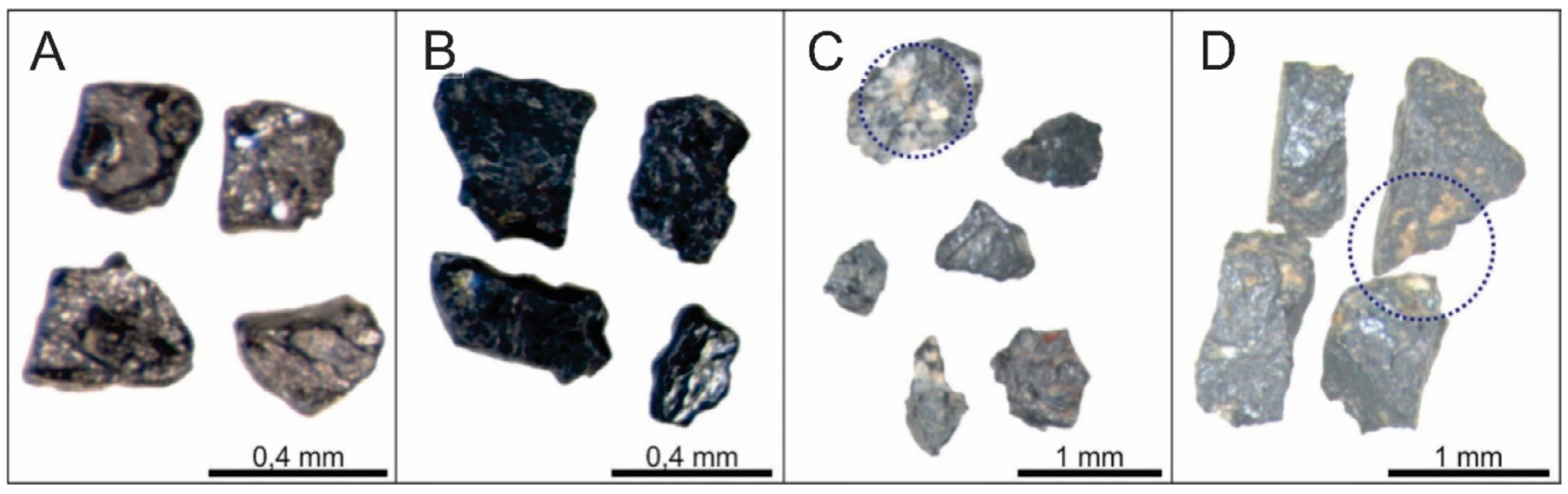

Figura 16. Ilmenita dos pegmatitos intrusivos no ortognaisse Resende Costa. (A) Grãos anédricos, achatados e com brilho metálico. Amostra do ponto TA-6; (B) grãos pretos, tabulares achatados e com brilho metálico. Amostra do ponto TA-8; (C) grãos anédricos, de cor cinza e parcialmente alterados para uma massa branca (destaque em azul), que corresponde a um óxido de Ti. Amostra do ponto TA-2B; (D) grãos subédricos, metálicos, cinza-claro e parcialmente alterados por oxidação para uma massa avermelhada (destaque em azul). Amostra do ponto TA-1B.
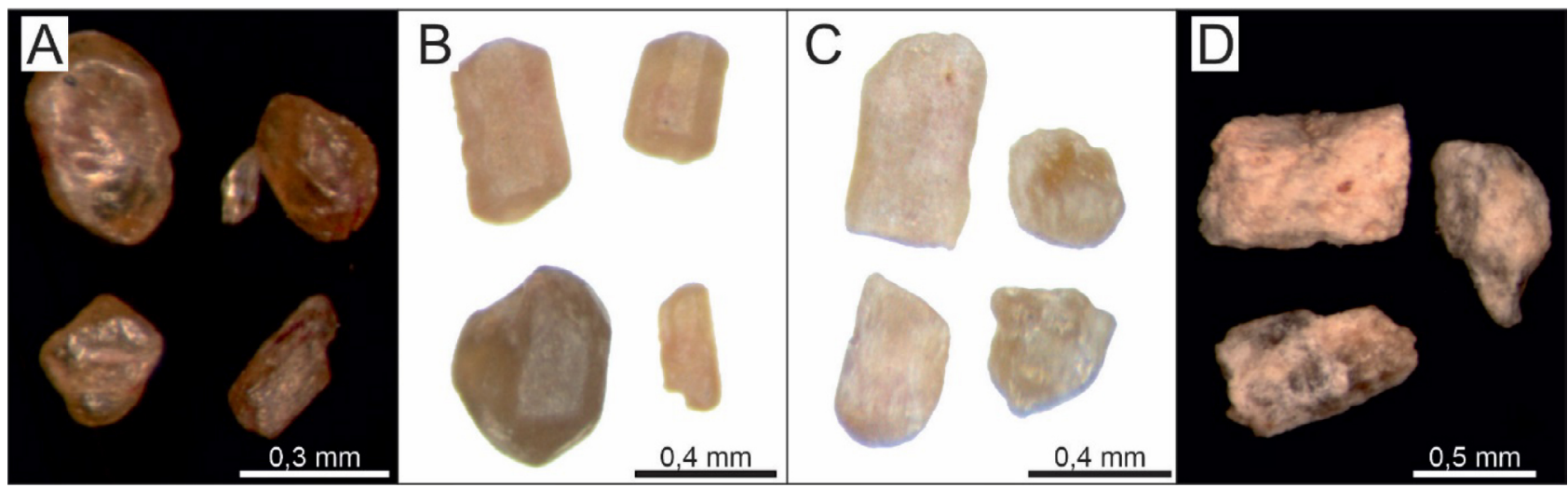

Figura 17. Monazita- $(\mathrm{Ce})$ dos pegmatitos intrusivos no ortognaisse Resende Costa. (A) Grãos subédricos com faces bem formadas, brilho vítreo e cor amarela. Amostra do ponto TA-7; (B) grãos euédricos, tabulares e esbranquiçados. Amostra do ponto LE-8; (C) grãos subédricos, tabulares e brancos. Amostra do ponto LE-2; (D) grãos anédricos, sacaroidais e recobertos por capa de alteração branca. Amostra do ponto TA-6.
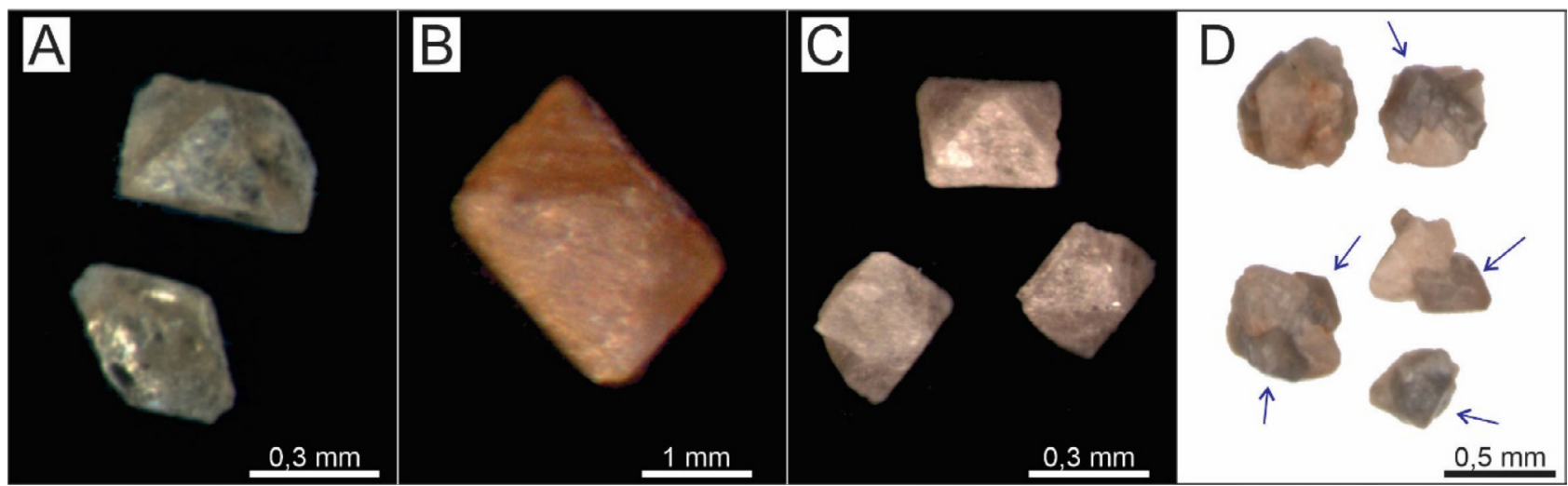

Figura 18. Xenotímio-(Y) dos pegmatitos intrusivos no ortognaisse Resende Costa. (A) Grãos euédricos, brancos, bipiramidais e com brilho vítreo. Amostra do ponto TA-4; (B) grão euédrico, bege, bipiramidal e translúcido. Amostra do ponto TA-7; (C) grãos euédricos, esbranquiçados, bipiramidais e translúcidos. Amostra do ponto TA-8; (D) grãos subédricos de xenotímio-(Y) intercrescidos com zircão (fase mais escura indicada pelas setas azuis). 
até resinoso (Figuras 18B, 18C e 18D) e cores bege, cinza, amarela e branca. Geralmente se encontra alterado e frequentemente ocorre intercrescido com zircão (Figura 18D).

\section{DISCUSSÃO}

Corpos pegmatíticos espacialmente correlatos e com mineralogia semelhante são normalmente interpretados como provenientes de uma mesma fonte. Esse é o caso de diversas províncias pegmatíticas ao redor do mundo, como as de Black Hills em Dakota do Sul, Estados Unidos da América (Norton e Redden, 1990; Shearer et al., 1992) e a Svecofennian/Svecokarelian, que se estende por Suécia, Finlândia e Rússia (Alviola et al., 2001; Mäkitie et al., 2001). No caso da Província Pegmatítica de São João del Rei, tanto os corpos da área do entorno da mina da Volta Grande (Guimarães e Guedes, 1944; Guimarães, 1956; Quéméneur, 1987; Lagache e Quéméneur, 1997; Assumpção, 2015; Alves, 2017) quanto os demais corpos pegmatíticos mineralizados ou não em cassiterita e em minerais do subgrupo da columbita (Rolff, 1948, 1952a; Francesconi, 1972; Pires e Porto Júnior, 1986; Pires e Pires, 1992; Pereira et al., 2008) foram correlacionados temporal e espacialmente ao metagranitoide Ritápolis, que possui proporção batolítica e idade de cristalização variando de $2149 \pm 10$ (Barbosa et al., 2015) a $2121 \pm 7 \mathrm{Ma}$ (Ávila, 2000).

A Tabela 3 sintetiza as principais informações referentes à mineralogia dos pegmatitos da Província Pegmatítica de São João del Rei, destacando-se que os corpos da mina da Volta Grande foram separados dos demais pegmatitos intrusivos nos anfibolitos da sequência metavulcanossedimentar Rio das Mortes descritos por Faulstich (2016). Optou-se por essa separação em razão de esses corpos terem sido minuciosamente caracterizados em relação à sua mineralogia (Lagache e Quéméneur, 1997; Assumpção, 2015; Alves, 2017) e por serem mineralogicamente diferentes dos demais pegmatitos, pois apresentam minerais de Li (espodumênio e lepidolita), enquanto fosfatos como monazita e xenotímio são muito raros. Na Tabela 3, não foram levados em consideração os minerais magnéticos (magnetita e pirrotita), enquanto minerais do supergrupo da granada foram separados conforme seus membros finais (composição química). Ilmenita, epidoto e/ou clinozoisita, zircão e minerais do supergrupo do pirocloro são encontrados em quase todos os pegmatitos e não foram considerados minerais discriminantes.

Destaca-se que a mineralogia dos pegmatitos intrusivos no ortognaisse Resende Costa difere fortemente daquela dos pegmatitos intrusivos no ortognaisse Cassiterita, em razão da presença de cassiterita e de minerais do subgrupo da columbita em todos os corpos estudados e de gahnita na maioria desses, enquanto aqueles intrusivos no ortognaisse Cassiterita são estéreis nesses três minerais (Tabela 3). Já os corpos da
Tabela 3. Principais minerais dos saprólitos de corpos pegmatíticos da Província Pegmatítica de São João del Rei e de rocha fresca do pegmatito da mina da Volta Grande.

\begin{tabular}{|c|c|c|c|c|c|c|c|}
\hline \multirow{2}{*}{$\begin{array}{l}\text { Minerais pesados } \\
\text { descritos nos } \\
\text { pegmatitos }\end{array}$} & \multicolumn{7}{|c|}{ Rocha encaixante dos pegmatitos } \\
\hline & 1 & 2 & 3a & $3 b$ & 4 & 5 & 6 \\
\hline Ilmenita & $x$ & $X$ & X & $x$ & $X$ & X & $x$ \\
\hline $\begin{array}{l}\text { Epidoto e/ou } \\
\text { clinozoisita }\end{array}$ & $x$ & $x$ & $x$ & $x$ & $x$ & $x$ & $x$ \\
\hline Zircão & $x$ & $X$ & $x$ & $X$ & $X$ & $x$ & $x$ \\
\hline $\begin{array}{l}\text { Supergrupo do } \\
\text { pirocloro }\end{array}$ & $x$ & $x$ & $x$ & $x$ & $x$ & $x$ & $x$ \\
\hline $\begin{array}{l}\text { Supergrupo da } \\
\text { turmalina }\end{array}$ & $x$ & $X$ & $x$ & $x$ & $x$ & $x$ & $x$ \\
\hline $\begin{array}{l}\text { Subgrupo da } \\
\text { columbita }\end{array}$ & $x$ & $x$ & $x$ & $x$ & - & $x$ & $x$ \\
\hline Cassiterita & $x$ & $X$ & $x$ & $x$ & - & $x$ & $x$ \\
\hline Gahnita & $x$ & $X$ & $x$ & $x$ & - & X & $x$ \\
\hline Xenotímio-(Y) & $x$ & $X$ & $x$ & $x$ & $X$ & - & $x$ \\
\hline Monazita-(Ce) & $x$ & $x$ & $x$ & $x$ & $x$ & $x$ & $x$ \\
\hline $\begin{array}{l}\text { Intercrescimento de } \\
\text { fases de } \mathrm{Nb}-\mathrm{Ta}-\mathrm{Ti}\end{array}$ & - & - & - & - & - & - & $x$ \\
\hline $\begin{array}{l}\text { Spessartina- } \\
\text { almandina }\end{array}$ & $x$ & $X$ & $x$ & $x$ & - & $x$ & - \\
\hline Spessartina & - & - & - & - & $X$ & - & $x$ \\
\hline $\begin{array}{l}\text { Spessartina- } \\
\text { grossulária }\end{array}$ & $x$ & - & - & - & - & $x$ & $x$ \\
\hline $\begin{array}{l}\text { Supergrupo do } \\
\text { anfibólio }\end{array}$ & $X$ & $X$ & - & $X$ & - & $x$ & - \\
\hline Grupo da apatita & $x$ & $X$ & - & $x$ & - & $x$ & - \\
\hline Bismutita & - & - & - & - & - & - & $x$ \\
\hline Galena & - & - & - & - & - & - & $x$ \\
\hline Anatásio & $x$ & - & $x$ & - & - & - & - \\
\hline Brookita & $x$ & - & - & - & - & - & - \\
\hline Rutilo & $x$ & - & - & $x$ & $x$ & - & $x$ \\
\hline Andaluzita & - & - & $X$ & - & - & - & - \\
\hline Estaurolita & - & - & $x$ & - & - & - & - \\
\hline Cianita & - & - & - & $X$ & - & - & - \\
\hline Espodumênio & - & - & - & - & - & $x$ & - \\
\hline Holmquistita & - & - & - & - & - & $x$ & - \\
\hline Micas litiníferas & - & - & - & - & - & $x$ & - \\
\hline Torita & - & - & - & $x$ & - & - & $x$ \\
\hline Thortveitita & - & - & - & - & - & - & $X$ \\
\hline Muscovita & $X$ & $x$ & $x$ & $x$ & $x$ & $x$ & $X$ \\
\hline Biotita & $X$ & - & - & - & $x$ & - & $X$ \\
\hline Hematita & - & - & - & - & - & - & $X$ \\
\hline Calcita & - & - & - & - & - & - & $X$ \\
\hline
\end{tabular}

1: Metagranitoide Ritápolis (Faulstich, 2016; Faulstich et al., 2016); 2: Metadiorito Brumado (Faulstich, 2016; Faulstich et al., 2016); 3a: filitos da sequência metavulcanossedimentar Rio das Mortes (Faulstich, 2016; Faulstich et al., 2016); 3b: anfibolitos da sequência metavulcanossedimentar Rio das Mortes (Faulstich, 2016; Faulstich et al., 2016); 4: ortognaisse Cassiterita (Faulstich, 2016); 5: anfibolitos na mina da Volta Grande (Francesconi, 1972; Assumpção, 2015; Alves, 2017); 6: ortognaisse Resende Costa (Cidade, 2019). 
mina da Volta Grande apresentam baixíssimo conteúdo de fosfatos de elementos terras raras (ETR), como xenotímio-(Y) e monazita-(Ce) (Alves, 2017), enquanto nos pegmatitos intrusivos nos ortognaisses Cassiterita e Resende Costa o xenotímio-(Y) é um mineral muito comum e a monazita-(Ce) está presente em todos os corpos do último litotipo e pode representar até $7 \%$ do total dos minerais pesados.

Em geral, a mineralogia descrita nos pegmatitos intrusivos no ortognaisse Resende Costa é semelhante àquela observada por Faulstich (2016) nos corpos pegmatíticos intrusivos no metagranitoide Ritápolis, no metadiorito Brumado e nos filitos e anfibolitos da sequência metavulcanossedimentar Rio das Mortes (Tabela 3), pois grande parte é mineralizada ora em minerais de $\mathrm{Nb}-\mathrm{Ta}$ (subgrupo da columbita e grupo da microlita), ora em minerais de Ti (ilmenita, anatásio, brookita e rutilo), ora em cassiterita. A grande diferença reside na presença do intercrescimento de fases de $\mathrm{Nb}$-Ta-Ti e de minerais do grupo do pirocloro somente nos corpos pegmatíticos intrusivos no ortognaisse Resende Costa.

Outras diferenças mineralógicas observadas nos corpos pegmatíticos dessa província correspondem:

- aos membros finais do supergrupo da granada. Todos os pegmatitos apresentam membros finais entre spessartina $(\mathrm{Mn})$ e almandina $(\mathrm{Fe})$. Corpos intrusivos no metagranitoide Ritápolis, nos anfibolitos da mina da Volta Grande e no ortognaisse Resende Costa também exibem grãos com composição intermediária entre spessartina e grossulária (Ca). Já o corpo TA-4 intrusivo no ortognaisse Resende Costa apresenta grãos com composição manganesífera (spessartina);

- à presença de minerais do supergrupo do anfibólio e do grupo da apatita. Esses foram descritos no exame de pegmatitos da mina da Volta Grande, bem como nos corpos intrusivos no metagranitoide Ritápolis, no metadiorito Brumado e nos anfibolitos da sequência metavulcanossedimentar Rio das Mortes. Nos pegmatitos intrusivos no ortognaisse Resende Costa esses minerais não foram identificados. Tais minerais, no entanto, podem ter sido eliminados pela alteração intempérica, apesar de se pressupor que a alteração tenha afetado a todas as exposições de forma equivalente;

- à presença de bismutita e galena em alguns dos pegmatitos intrusivos no ortognaisse Resende Costa e à ausência desses minerais nos demais pegmatitos da Província Pegmatítica de São João del Rei;

- à cassiterita presente nos pegmatitos intrusivos no ortognaisse Resende Costa comumente em associação com o intercrescimento de fases de $\mathrm{Nb}$-Ta-Ti, enquanto nos demais corpos pegmatíticos da província essa associação não é observada e a cassiterita ocorre como grãos livres;

- aos polimorfos de Ti. Anatásio foi identificado nos pegmatitos intrusivos no metagranitoide Ritápolis e nos filitos da sequência metavulcanossedimentar Rio das Mortes, enquanto brookita foi observada apenas nos corpos que intrudem o metagranitoide Ritápolis. Rutilo está presente em vários pegmatitos, com exceção daqueles intrusivos no metadiorito Brumado, nos filitos da sequência metavulcanossedimentar Rio das Mortes, no ortognaisse Cassiterita e nos corpos da mina da Volta Grande;

- a andaluzita, estaurolita e cianita encontradas em pegmatitos que intrudem as rochas da sequência metavulcanossedimentar Rio das Mortes e que não foram observadas nos pegmatitos que intrudem o ortognaisse Resende Costa;

- aos minerais de Li, como espodumênio, holmquistita e lepidolita, não identificados nos concentrados de minerais pesados dos saprólitos dos pegmatitos intrusivos no ortognaisse Resende Costa. Esses estão presentes apenas nos corpos da mina da Volta Grande, onde foram estudados pegmatitos frescos. A alteração intempérica pode ser a responsável pela ausência desses minerais nos saprólitos;

- à ocorrência de torita nos pegmatitos intrusivos no ortognaisse Resende Costa e nos anfibolitos da sequência metavulcanossedimentar Rio das Mortes, enquanto a thortveitita está somente presente em parte dos pegmatitos intrusivos no ortognaisse Resende Costa.

Observou-se que na Província Pegmatítica de São João del Rei ocorrem três conjuntos de pegmatitos com mineralogias, fontes e idades diferentes. O conjunto mais antigo é caracterizado pela presença de minerais do grupo da microlita e pela ausência de cassiterita e minerais do subgrupo da columbita. Os pegmatitos desse conjunto apresentam idade U-Pb LA-ICPMS de $2489 \pm 10 \mathrm{Ma}$ (Faulstich, 2016) e são intrusivos no ortognaisse Cassiterita, cuja idade de cristalização varia entre $2472 \pm 11$ e $2414 \pm 29 \mathrm{Ma}$ (Barbosa et al., 2019). O conjunto mais novo é mineralizado em cassiterita, gahnita e minerais do subgrupo da columbita, possui idade U-Pb LA-ICPMS variando entre $2129 \pm 33$ e $2121 \pm$ $9 \mathrm{Ma}$ (Faulstich, 2016) e é intrusivo em filitos e anfibolitos da sequência metavulcanossedimentar Rio das Mortes, bem como no metadiorito Brumado e no metagranitoide Ritápolis, que são corpos plutônicos do Cinturão Mineiro. O terceiro conjunto de pegmatitos é intrusivo no ortognaisse Resende Costa e caracterizado pela presença do intercrescimento de fases de $\mathrm{Nb}$-Ta-Ti e de minerais do grupo do pirocloro. Diniz-Pinto et al. (2004) apontaram que o pegmatito da Volta Grande teria idade $\mathrm{Pb}-\mathrm{Pb}$ em zircão de $2207 \pm$ $13 \mathrm{Ma}$ e, dessa maneira, poderia corresponder a um quarto conjunto de pegmatitos, pois sua mineralogia e idade são muito diferentes dos três demais conjuntos.

Com a evolução do conhecimento sobre os pegmatitos da Província Pegmatítica de São João del Rei, dois grandes problemas surgem: 
- Segundo Assumpção (2015) e Alves (2017), os corpos da área da Volta Grande seriam do tipo LCT, ou seja, enriquecidos em minerais de Li (espodumênio, micas litiníferas), Cs (polucita, K-feldspato, micas) e Ta (tantalita-Fe e tantalita-Mn, grupo da microlita), que contrastam com os demais pegmatitos da província, que se assemelham a corpos do tipo NYF, pois o conteúdo de $\mathrm{Nb}$ é muito maior do que o de Ta nos minerais do subgrupo da columbita, bem como apresentam minerais de $\mathrm{Y}$ como o xenotímio-(Y). Entretanto, até o momento, nenhum mineral contendo $\mathrm{F}$ foi identificado nesses corpos;

- Os corpos da área da mina da Volta Grande foram correlacionados temporal e espacialmente ao plúton que aflora no entorno da cidade de Ritápolis, que possui proporção batolítica e idade de cristalização variando de 2149 $\pm 10 \mathrm{Ma}$ (Barbosa et al., 2015) a $2121 \pm 7 \mathrm{Ma}$ (Ávila, 2000). Entretanto, Diniz-Pinto et al. (2004) apontaram que os pegmatitos dessa área possuiriam idade de 2207 $\pm 13 \mathrm{Ma}$, ou seja, cerca de $80 \mathrm{Ma}$ mais velhos que o metagranitoide. Nesse caso, esses corpos não poderiam ter o referido metagranitoide como fonte e outro corpo do Cinturão Mineiro seria o responsável pelas mineralizações pegmatíticas na área da mina da Volta Grande.

\section{CONCLUSÕES}

$\mathrm{O}$ fino intercrescimento de fases de Nb-Ta-Ti se mostra determinante para caracterizar os pegmatitos intrusivos no ortognaisse Resende Costa, uma vez que esse só ocorre nesses corpos. Em relação à mineralogia, os pegmatitos intrusivos no ortognaisse Resende Costa diferem da geração associada ao ortognaisse Cassiterita por serem mineralizados em cassiterita, minerais do subgrupo da columbita e em gahnita. Diferem da geração de pegmatitos associada ao metagranitoide Ritápolis por apresentarem minerais do grupo do pirocloro, bismutita e galena, bem como por não exibirem minerais do supergrupo do anfibólio e do grupo da apatita. Destaca-se ainda que nos pegmatitos intrusivos no ortognaisse Resende Costa a cassiterita se encontra normalmente em associação com o intercrescimento de fases de $\mathrm{Nb}-\mathrm{Ta}-\mathrm{Ti}$, enquanto nos demais corpos da província essa associação não é observada e a cassiterita ocorre como mineral livre.

\section{AGRADECIMENTOS}

Taís Proença Cidade e Ciro Alexandre Ávila agradecem à Fundação de Amparo à Pesquisa do Estado do Rio de Janeiro (FAPERJ - processos E-26/201.042/2017 e E-26/200.092/2019) a concessão da bolsa de Mestrado e o auxílio à pesquisa; Ciro Alexandre Ávila e Reiner
Neumann, ao Conselho Nacional de Desenvolvimento Científico e Tecnológico (CNPq) as bolsas de produtividade (307260/2017-8 e 315472/2018-9, respectivamente) e o projeto de apoio (406853/2013-4); os autores, ao Centro de Tecnologia Mineral (CETEM) e ao Departamento de Geologia e Paleontologia do Museu Nacional a disponibilização dos equipamentos e infraestrutura.

\section{REFERÊNCIAS}

Alves, F. E. A. (2017). Caracterização mineralógica do minério de Sn-Nb-Ta-Li da mina da Volta Grande, com enfoque nos minerais carreadores de elementos terras raras. Dissertação (Mestrado). Rio de Janeiro: Instituto de Geociências, UFRJ.

Alves, F. E. A., Neumann, R., Ávila, C. A., Faulstich, F. R. L. (2019). Monazite-(Ce) and xenotime-(Y) microinclusions in fluorapatite of the pegmatites from the Volta Grande mine, Minas Gerais state, southeast Brazil, as witnesses of the dissolution-reprecipitation process. Mineralogical Magazine, 83(4), 595-606. https://doi.org/10.1180/mgm.2019.43

Alviola, R., Mänttäri, I., Mäkitie, H., Vaasjoki, M. (2001). Svecofennian rare-element granitic pegmatites of the Ostrabothnia region, western Finland, their metamorphic environment and time of intrusion. Geological Survey of Finlan, 30, 9-29. Disponível em: <http:/tupa.gtk.fi/julkaisu/ specialpaper/sp_030_pages_009_029.pdf $>$. Acesso em: 24 jul. 2020.

Assumpção, C. S. (2015). Caracterização mineralógica e geoquímica do pegmatito da mina de Volta Grande, província pegmatítica de São João del Rei, Nazareno, Minas Gerais. Dissertação (Mestrado). Ouro Preto: Escola de Minas, UFOP. Disponível em: <http://www.repositorio.ufop.br/ handle/123456789/5986>. Acesso em: 24 jul. 2020.

Ávila, C. A. (2000). Geologia, petrografia e geocronologia de corpos plutônicos Paleoproterozóicos da borda meridional do Cráton São Francisco, região de São João del Rei, Minas Gerais. Tese (Doutorado). Rio de Janeiro: Instituto de Geociências, UFRJ.

Ávila, C. A., Guerra, F. G., Teixeira, W., Dussin, I. A., Silveira, V. L., Bongiolo, E. M. (2015). Petrografia, geoquímica e geocronologia do ortognaisse granodiorítico Ribeirão dos Mosquitos, região sul de Resende Costa, Minas Gerais. XIV Simpósio de Geologia do Sudeste. Campos do Jordão: SBG. p. 321. Disponível em: <http://sbg.sitepessoal.com/ anais_digitalizados/simposiodosudeste/2015.pdf $>$. Acesso em: 24 jul. 2020. 
Ávila, C. A., Teixeira, W., Bongiolo, E. M., Dussin, I. A., Vieira, T. A. T. (2014). Rhyacian evolution of subvolcanic and metasedimentary rocks of the southern segment of the Mineiro Belt, São Francisco Craton, Brazil. Precambrian Research, 243, 221-251. https://doi.org/10.1016/j.precamres.2013.12.028

Ávila, C. A., Teixeira, W., Cordani, U. G., Barrueto, H. R., Pereira, R. M., Martins, V. T. S., Dunyi, L. (2006). The Glória quartz-monzodiorite isotopic and chemical evidence of arcrelated magmatism in the central part of the Paleoproterozoic Mineiro Belt, Minas Gerais State, Brazil. Anais da Academia Brasileira de Ciências, 78(3), 543-556. https://doi.org/10.1590/S0001-37652006000300013

Ávila, C. A., Teixeira, W., Cordani, U. G., Moura, C. A. V., Pereira, R. M. (2010). Rhyacian (2.23-2.20 Ga) juvenile accretion in the southern Sao Francisco Craton, Brazil: geochemical and isotopic evidence from the Serrinha magmatic suite, mineiro belt. Journal South American Earth Science, 29(2), 464-482. https://doi.org/10.1016/j.jsames.2009.07.009

Ávila, C. A., Teixeira, W., Vasques, F. S. G., Dussin, I. A., Mendes, J. C. (2012). Geoquímica e idade U-Pb (LA-ICPMS) da crosta oceânica anfibolítica riaciana do Cinturão Mineiro, borda meridional do Cráton São Francisco. XLVI Congresso Brasileiro de Geologia. Santos: SBG. Disponível em: $<$ http://www.sbgeo.org.br/home/pages/44\#Anais\%20de\%20 Congressos\%20Brasileiros $\% 20 \mathrm{de} \% 20$ Geologia $>$. Acesso em: 24 jul. 2020.

Barbosa, N. S., Teixeira, W., Ávila, C. A., Montecinos, P. M., Bongiolo, E. M. (2015). 2.17-2.10 Ga plutonic episodes in the Mineiro Belt, São Francisco Craton, Brazil: U-Pb ages, geochemical constraints and tectonics. Precambrian Research, 270, 204-225. https://doi.org/10.1016/j.precamres.2015.09.010

Barbosa, N., Teixeira, W., Ávila, C. A., Montecinos, P. M., Bongiolo, E. M., Vasconcelos, F. F. (2019). U-Pb geochronology and coupled Hf-Nd-Sr isotopic-chemical constraints of the Cassiterita Orthogneiss (2.47-2.41-Ga) in the Mineiro belt, São Francisco Craton: geodynamic fingerprints beyond the Archean-Paleoproterozoic transition. Precambrian Research, 326, 399-416. https:// doi.org/10.1016/j.precamres.2018.01.017

Cardoso, C. D., Ávila, C. A., Neumann, R., Oliveira, E. P., Valeriano, C. M., Dussin, I. A. (2019). A Rhyacian continental arc during the evolution of the Mineiro belt, Brazil: constraints from Rio Grande and Brumado metadiorites. Lithos, 326327, 246-264. https://doi.org/10.1016/j.lithos.2018.12.025

Cidade, T. P. (2019). Mineralogia e idade dos pegmatitos intrusivos no ortognaisse Resende Costa, Província
Pegmatítica de São João del Rei, Minas Gerais. Dissertação (Mestrado). Rio de Janeiro: Museu Nacional, UFRJ.

Coelho, I. S. (1942). Ocorrência de cassiterita em São João del Rei, Estado de Minas Gerais. Mineração e Metalurgia, 6, 288-289.

Correia Neves, J. M., Soares, A. C. P., Marciano, V. R. P. R. O. (1986). A Província Pegmatítica Oriental à luz dos conhecimentos atuais. Revista Brasileira de Geociências, 16(1), 106-118. Disponível em: $<$ http://www.ppegeo.igc.usp. br/index.php/rbg/article/view/12028>. Acesso em: 24 jul. 2020.

Dias, M. B., Wilson, W. E. (2000). The Alto Ligonha Pegmatites Mozambique. The Mineralogical Record, 31(6), 459-497.

Diniz-Pinto, H. S., Todt, W., Hofmeister, W. (2004). Aspectos texturais de microlitas dos pegmatitos de Volta Grande, Nazareno, MG. XLII Congresso Brasileiro de Geologia. Araxá: SBG. p. 620-621. Disponível em: <http://sbg.sitepessoal. com/anais_digitalizados/2004-ARAX\%C3\%81/2004ARAX\%C3\%81.zip>. Acesso em: 24 jul. 2020.

Faulstich, F. R. L. (2016). Estudo de minerais pesados dos pegmatitos da Província Pegmatítica de São João del Rei, Minas Gerais. Tese (Doutorado). Rio de Janeiro: Instituto de Geociências, UFRJ.

Faulstich, F. R. L., Ávila, C. A., Neumann, R., Silveira, V. S. L., Callegario, L. S. (2016). Gahnite from the São João del Rei pegmatitic province, Minas Gerais, Brazil: chemical composition and genetic implications. Canadian Mineralogist, 54, 1385-1402. https://doi.org/10.3749/canmin.1500091

Francesconi, R. (1972). Pegmatitos da Região de São João Del Rei, $M G$. Tese (Doutorado). São Paulo: Instituto de Geociências, USP. https://doi.org/10.11606/T.44.2016. tde-01022016-103945

Guimarães, D. (1950). A jazida de djalmaíta de Volta Grande Rio das Mortes, Minas Gerais. Anais da Academia Brasileira de Ciências, 22(1), 51-71.

Guimarães, D. (1956). Concentrados estaníferos do município de São João del Rei, Minas Gerais. Avulso do Departamento Nacional Produção Mineral, 99, 43-72.

Guimarães, D., Belezkij, V. (1956). The stano-tantalouraniferous deposits and occurrences in the region of São João del Rei, Minas Gerais, Brazil. VI International Conference On The Peaceful Uses Of Atomic Energy. Genebra. 6, p. 143-146. 
Guimarães, D., Guedes, S. V. (1944). Nota preliminar sobre a região estanífera de São João Del Rei, Minas Gerais. Avulso do Departamento Nacional Produção Mineral, 58, 13-26.

Heinrich, E. W. (1964). Tin-tantalum-lithium pegmatites of the São João del Rei district, Minas Gerais, Brazil. Economic Geology, 59(6), 982-1002. https://doi.org/10.2113/ gsecongeo.59.6.982

International Centre for Diffraction Data (ICDD). (2020) PDF4+ Relational Powder Diffraction File. Disponível em: $<$ https://www.icdd.com/pdf-4/>. Acesso em: 19 ago. 2018.

Krippner, A., Meinhold, G., Morton, A. C., Schönig, J., Von Eynatten, H. (2016). Heavy minerals and garnet geochemistry of stream sediments and bedrocks from the Almklovdalen area, Western Gneiss Region, SW Norway: Implications for provenance analysis. Sedimentary Geology, 336, 96-105. https://doi.org/10.1016/j.sedgeo.2015.09.009

Lafuente, B., Downs, R. T., Yang, H., Stone, N. (2015). The power of databases: the RRUFF project. In: T. Armbruster, R. M. Danisi (Coords.), Highlights in Mineralogical Crystallography (p. 1-30). Berlim: De Gruyter.

Lagache, M., Quéméneur, J. J. G. (1997). The Volta Grande pegmatites, Minas Gerais, Brazil: an example of rare-element granitic pegmatites exceptionally enriched in lithium and rubidium. Canadian Mineralogist, 35(1), 153-165. Disponível em: $<$ https://pubs.geoscienceworld.org/canmin/articleabstract/35/1/153/12839/The-Volta-Grande-PegmatitesMinas-Gerais-Brazil-an?redirectedFrom $=$ fulltext $>$. Acesso em: 24 jul. 2020.

London, D. (2008). Pegmatites. Quebec: Mineralogical Association of Canada.

Mäkitie, H., Kärkkäinen, N., Lahti, S. I., Alviola, R. (2001). Compositional variation of granitic pegmatites in relation to regional metamorphism in the Seinäjoki region, western Finland. In: H. Makitie (ed.), Svecofennian Granitic Pegmatites (1.86-1.79 Ga) and Quartz Monzonite (1.87 $\mathrm{Ga}$ ), and Their Metamorphic Environment in the Seinäjoki Region, Western Finland. Geological Survey of Finland, Special Paper, 30, 31-59.

Mange, M. A., Maurer, H. F. W. (1992). Heavy Minerals in Colour: Chapman and Hall. Londres: Cambridge University.

Mange, M. A., Morton, A. C. (2007). Geochemistry of heavy minerals. In: M. A. Mange, D. T. Wright (Coord.), Heavy Minerals, 345-391. Developments in Sedimentology. Amsterdã: Elsevier.
Morton, A. C., Smale, D. (1990). The effects of transport and weathering on heavy minerals from the Cascade River, New Zealand. Sedimentary Geology, 68(1-2), 117-123. https:// doi.org/10.1016/0037-0738(90)90122-A

Norton, J. J., Redden, J. A. (1990). Relations of zoned pegmatites to other pegmatites, granite, and metamorphic rocks in the southern Black Hills, South Dakota. American Mineralogist, 75(5-6), 631-655. Disponível em: $<$ https://pubs.geoscienceworld. org/msa/ammin/article-abstract/75/5-6/631/42382/Relationsof-zoned-pegmatites-to-other-pegmatites?redirectedFrom $=\mathrm{fu}$ lltext $>$. Acesso em: 24 jul. 2020.

Parfenoff, A., Pomerol, C., Toureng, J. (1970). Les minéraux en grains: Méthodes d'études et determination. Paris: Masson et Cie.

Pereira, R. M. (2012). Fundamentos de Prospecção Mineral. 2. ed. Rio de Janeiro: Interciências.

Pereira, R. M., Ávila, C. A., Lima, P. R. A. S. (2005). Minerais em Grãos: técnicas de coleta, preparação e identificação. São Paulo: Oficina de Textos.

Pereira, R. M., Ávila, C. A., Moura, C. A. V., Couto, F. M., Dutra, D. C. (1998). Presença de galena e de uma anomalia geoquímica de $\mathrm{Pb}$ na região entre Nazareno e São João del Rei, Minas Gerais. XL Congresso Brasileiro de Geologia. Belo Horizonte: SBG. p. 334. Disponível em: $<$ http:// sbg.sitepessoal.com/anais_digitalizados/1998-BELO $\% 20$ HORIZONTE/CBG1998.pdf $>$. Acesso em: 24 jul. 2020.

Pereira, R. M., Ávila, C. A., Neumann, R. (2004). Estudo mineralógico e químico da cassiterita e de suas inclusões sólidas: implicação com a paragênese das mineralizações da Província Pegmatítica de São João del Rei, Minas Gerais, Brasil. Arquivos do Museu Nacional, 62(3), 321-336.

Pereira, R. M., Ávila, C. A., Neumann, R. (2007). Ocorrências de zircão hafnífero no sudeste brasileiro. Revista Brasileira de Geociências, 37(2), 215-223. https:// doi.org/10.25249/0375-7536.2007373445463215223

Pereira, R. M., Ávila, C.A., Neumann, R., Netto, A. M., Atencio, D. (2003). Borda de hafnão zirconífero em zircão hafnífero da mina do Volta Grande, Província Pegmatítica de São João del Rei, Minas Gerais, Brasil. Boletim do Museu Nacional, (69), 1-14.

Pereira, R. M., Neumann, R., Ávila, C. A., Castro, C. (2008). Determinação da gênese da cassiterita com base na sua composição química e inclusões minerais: ocorrências no sul e sudeste brasileiro. Revista Brasileira de Geociências, 38(2), 246-252. Disponível em: <http://ppegeo.igc.usp.br/ index.php/rbg/article/view/7581>. Acesso em: 24 jul. 2020. 
Pettijohn, F. J. (1941). Persistence of heavy minerals and geologic age. Journal of Geology, 49(6), 610-625. Disponível em: <https://www.jstor.org/stable/30079640>. Acesso em: 24 jul. 2020.

Pettijohn, F. J. (1975). Sedimentary Rocks. 2. ed. Nova York: Harper and Row.

Pires, F. R. M., Pires, H. L. (1992). Regional zoning in the São João del Rei Pegmatite District and its relation with the Collisional Santa Rita Granite, Minas Gerais, Brazil. XXXVII Congresso Brasileiro de Geologia. São Paulo: SBG. p. 269-272. Disponível em: <http://www.sbgeo.org. br/home/pages/44>. Acesso em: 24 jul. 2020.

Pires, F. R. M., Porto Júnior, R. (1986). A mineralização de Sn-Ta-Nb-Li e o Granito Santo Rita, São João Del Rey, Minas Gerais. XXXIV Congresso Brasileiro de Geologia. Goiânia: SBG. p. 2023-2024. Disponível em: <http://www. sbgeo.org.br/home/pages/44>. Acesso em: 24 jul. 2020.

Quéméneur, J. J. G. (1987). Petrography of the pegmatites from Rio das Mortes Valley, southeast Minas Gerais, Brazil. Revista Brasileira de Geociências, 17(4), 595-600. Disponível em: <http://www.ppegeo.igc.usp.br/index.php/rbg/article/ view/11984>. Acesso em: 24 jul. 2020.

Quéméneur, J. J. G., Baraud, E. R. (1983). Estrutura do embasamento Arqueano e geologia econômica da área pegmatítica de São João Del Rei - MG. II Simpósio de Geologia de Minas Gerais. Belo Horizonte: SBG. p. 449-460.

Rolff, P. A. M. A. (1947). A Província Estanífera do Rio das Mortes, Minas Gerais. Revista da Escola de Minas, 12, 25-27.

Rolff, P. A. M. A. (1948). A Província Estanífera do Rio das Mortes. Revista da Escola de Minas, 13, 5-20.

Rolff, P. A. M. A. (1951). Nota sobre a geologia da Serra do Lenheiro. Revista da Escola de Minas, 16, 31-36.

Rolff, P. A. M. A. (1952a). Geologia da Província EstanoLitinífera do Rio das Mortas, Minas Gerais. Revista da Escola de Minas, 17, 3-40.
Rolff, P. A. M. A. (1952b). Urânio e tório em São João del Rei. Revista da Escola de Minas, 17, 11-12.

Santos, R. A., Pereira, R. M. (1983). Nota sobre a ocorrência de scheelita na região de São Tiago, Nazareno e Cassiterita, M.G. Mineração \& Metalurgia, 444, 32-33.

Shearer, C. K., Papike, J. J., Joliff, B. L. (1992). Petrogenetic links among granites and pegmatites in the Harney Peak rare-element granite-pegmatite system, Black Hills, South Dakota. Canadian Mineralogist, 30(3), 785-809. Disponível em: <https://pubs. geoscienceworld.org/canmin/article-abstract/30/3/785/12400/ Petrogenetic-links-among-granites-and-pegmatites?redirected From=fulltext $>$. Acesso em: 24 jul. 2020.

Teixeira, W., Ávila, C. A., Dussin, I. A., Corrêa Neto, A., Bongiolo, E. M., Santos, J. O., Barbosa, N. S. (2015). A juvenile accretion episode $(2.35 \mathrm{e} 2.32 \mathrm{Ga})$ in the mineiro belt andits role to the Minas accretionary orogeny: zircon $\mathrm{U}$ e $\mathrm{Pb}$ e Hf and geochemical evidences. Precambrian Reserach, 256, 148-169. https://doi.org/10.1016/j.precamres.2014.11.009

Teixeira, W., Ávila, C. A., Nunes, L. C. (2008). Nd-Sr isotopic geochemistry and $\mathrm{U}-\mathrm{Pb}$ geochronology of Fé granitic gneiss and Lajedo granodiorite: implications for Paleoproterozoic evolution of the Mineiro belt, southern São Francisco Craton. Geologia USP. Série Científica, 8(1), 53-74. https://doi.org/10.5327/Z1519-874x2008000100005

Terry, R. D., Chilingar, G. V. (1955). Summary of "Concerning some addicional aids in studying sedimentary formations". Journal of Sedimentar Petrology, 25(3), 229-234. https://doi. org/10.1306/74D70466-2B21-11D7-8648000102C1865D

Valença, J. G., Silva, M. A., Schimdt, R. S., Trouw, R. A. J., Noce, C. M. (2000). Transamazonian gabronoritic intrusive rocks from the southernmost São Francisco Craton, Brazil. XXXI International Geological Congress. Rio de Janeiro. CD-ROM.

Vieira, T. A. T. (2015). Geologia, petrografia, geoquímica e geocronologia do metagabro Vitoriano Veloso e sua relação com o Cinturão Mineiro. Dissertação (Mestrado). Rio de Janeiro: Instituto de Geociências, UFRJ. 